UNIVERSIDADE ESTADUAL PAULISTA “JULIO DE MESQUITA FILHO” FACULDADE DE MEDICINA

CAMPUS DE BOTUCATU

\title{
PERFIL DE CITOCINAS INFLAMATÓRIAS EM INDIVÍDUOS SUBMETIDOS A PROCEDIMENTOS CIRÚRGICOS UTILIZANDO PROPOFOL OU ISOFLURANO
}

\section{MARINA ÁZER MAZOTI}

\begin{abstract}
Dissertação apresentada ao Programa de Pós-Graduação em Patologia da Faculdade de Medicina de Botucatu, Universidade Estadual Paulista UNESP, para obtenção do titulo de Mestre em Patologia.
\end{abstract}

BOTUCATU - SP 
UNIVERSIDADE ESTADUAL PAULISTA “JULIO DE MESQUITA FILHO” FACULDADE DE MEDICINA

CAMPUS DE BOTUCATU

\section{PERFIL DE CITOCINAS INFLAMATÓRIAS EM INDIVÍDUOS SUBMETIDOS A PROCEDIMENTOS CIRÚRGICOS UTILIZANDO PROPOFOL OU ISOFLURANO}

Mestranda: MARINA ÁZER MAZOTI

Orientadora: Dra. DENISE FECCHIO

Dissertação apresentada ao Programa de Pós-Graduação em Patologia da Faculdade de Medicina de Botucatu, Universidade Estadual Paulista UNESP, para obtenção do titulo de Mestre em Patologia.

BOTUCATU - SP 
FICHA CATALOGRÁFICA ELABORADA PELA SEÇÃO TÉCNICA DE AQUISIÇÃO E TRATAMENTO DA INFORMAÇÃO

DIVISÃO TÉCNICA DE BIBLIOTECA E DOCUMENTAÇÃO - CAMPUS DE BOTUCATU - UNESP BIBLIOTECÁRIA RESPONSÁVEL: Selma Maria de Jesus

Mazoti, Marina Ázer.

Perfil de citocinas inflamatórias em indivíduos submetidos a procedimentos cirúrgicos utilizando propofol ou isoflurano/Marina Ázer Mazoti. - Botucatu: [s.n.], 2010.

Dissertação (mestrado) - Faculdade de Medicina de Botucatu, Universidade Estadual Paulista, 2010.

Orientador: Denise Fecchio

Assunto CAPES: 40101134

1. Patologia cirúrgica 2. Citocinas inflamatórias 3. Stress

CDD 617.07

Palavras-chave:Cirurgia eletiva; Citocinas inflamatórias; Isoflurano; Propofol; Stress 
Dedicatárias 
À minha mãe. Lilian.

Pela amor e carinho.

Pelo apoia nos momentos dificeis.

Por dividir comiga tristezas e alegrias.

Pela exempla de dedicaçãa.

Pelas palauras amigas em todas as momentas.

Ao men pai. Lourival.

Pelo carinho e amizade.

Pela apaia e compreensãa em cada momenta.

"Há homens que lutam un dia e sãa bans. Há outros que lutam un ano e sãa melhores. Existem aqueles que lutam muitas anos $e$ sãa muita bans. Parém, existem as que lutam tada a vida, esses sãa imprescindíueis. 
À minha irmã. Priscila.

Pela amor e carinha.

Pela compreensãa nos momentos difíceis.

Pela seu exempla de farca.

E par seu humor contagiante!

À minha avá. Leny. (in memarian)

Pela exempla de sabedoria e fé.

to Guilherme,

Pela carinho e amor.

Pelas palauras de incentiva em qualguer circunstância.

"As coisas tangíueis tornam-se insensiveis à palma da mãa.

Mas as caisas findas, muita mais que lindas, essas ficarãa.

(Carlos Drummond de Andrade) 
A minha orientadora. Denise Fecchia.

Por acreditar que era passível.

Pela carinha, arientaçãa e dedicaçãa.

Pela constante apaia.

"De tuda ficam três coisas: a certeza de que está sempre comecanda, a certeza de que era precisa continuar e a certeza de que seria interrompida antes de terminar. Fazer da interrupçãa un caminho nova. fazer da queda um passa de danca. da meda uma escada, da sonha uma pante, da procura um encantra"

(Fermanda Sabina) 


\section{Agradecimentas}


A Deus

Pela dam da vida e eterna amor.

Por ter aberto caminhos.

Agradeça par ter comiga a Sua mãa.

Agradeça pela familia e amigos.

"Bam é render graças aa Senhor. Ecantar lanwores ar 7eu nome, á Altíssima" (se 92:1) 
Aas professares Drs.

Daisy M. 7. Saluadorie

Jasé Reinalda Cerqueira Braz.

Pela apoia desde a inicia deste trabalha.

Pela dedicaçãa, arientaçãa e inestimável auxília.

A Mariana Gobba Braz.

Pela constante apoia, auxilia, incentiva...

Por incansavelmente me ajudar no desenvoluimento deste trabalho.

Por incentivar a meu crescimenta.

Pela amizade e forca em tados as momentos.

Ao Leandra Gobba Braz e à Märjorie de Assis Golim.

Por me auxiliarem neste trabalho.

Por ajudarem a tornar este projeta realidade. 
Agradeça a todos que me apaiaram e àqueles que ajudaram no desenualuimenta e cancretizaçãa deste trabalha.

Aos pacientes e voluntários que doaram um pauca de si.

Aa Dr. Jasé Reinalda Braz e aa Leaudra Braz pela busca par pacientes e coleta de suas amostras.

A todos as residentes dos departamentas de Anestesiologia $e$ Oftalmalogia. Otarrinolaringologia e Cirurgia de Cabeça e Pescaça pela realizaçãa das pracedimentas anestésica-cirúrgicas.

A Mariana pela prazerosa convivia no dia-a-dia do labaratória. Pela auxilia e apoia antes mesma de este projeta existir.

À Márjarie de Assis Golim, pela seu auxilia e encorajamento durante as experimentos. Por me apresentar à Citometria de Fluxa.

Aa Prof. Dr. Carlas Padauani, pela excelente auxilia na análise estatística.

Aa Radriga Pestana, assessor cientéfica da empresa BD, e demais funcionários da empresa. pela auxilia na análise das amostras. 
A Dra. Angela M. V. C. Soares, por ter me acolhido assim que chequei à Botucatu e par participar de minha caminhada durante a pás-graduaçãa.

Aa dr. Dulia Defaveri, pelos ensinamentas em Patalogia e pela exempla de vida.

Aa colega Jasé Eduarda Orasz pelas ensinamentos em Anestesialogia e discussãa de resultados.

Aos funcionários da seçãa de Pós-Graduaçãa Danete Silua. Andrea Devidé, Lilian Nunes, Regina Spadin e Nathanael Salles. As secretárias de Pós-Graduaçãa em Patologia. Tânia Andrade eVânia Soler, por me sanarem as dividas pertinentes.

Aos funcianários da Centra Cirúrgica, do departamenta de Patalogia e da Hemacentra, da Faculdade de Medicina de Botucatur, pela auxilia was coletas das amostras, no seu processamenta e na sua análise, respectivamente.

Aos amigos e funcionários do Hemocentra de Botucatu: Cléa. Fátima (7ata). Priscila Murador. Maércia, Regina, Lilian.

Á Léia (Valéria) e a Gustaua, do labaratória de Citometria de Fluxa, pela incansáuel auxilia durante as experimentos. 
Aa Claudinei Fiqueira. Luciana Danini. Maria Luiza Ardanaz (Mara). Paula (Taxican) e Cristina Darica, funcionários do departamenta de Patalogia. sempre dispostos a auxiliar no que fosse necessária.

A Laura 7. Castra. Claudinei (Crá). Izaíra M. Carualha (Duju) e aa Joãa 7. Lunizutta e Lizia C. Vilela, pelos ensinamentos deurante a Aprimaramenta.

A Rita C. S. Bruder, nãa sá pelas ensinamentos enquanto aprimaranda, mas pelos ensinamentas de vida e por se mostrar uma grande amiga. A wace. Laurinha e Nelsan Bruder men meita abrigada pelas acolhidas!

Ao Igor Minatel, amiga pra todas as horas. Muito abrigada par me acudir em qualquer circunstância. Obrigada pela amizade sincera.

Aos meus amigos pós-graduandos, entre eles: Shadia Thlaseh. Jaãa Luvizutto, Bruna Ramas, Jossimara Polettini. Viviane Pascatta. Caral.. Vacês sãa muita queridas.

As minhas amigas, carana pra todas as horas. sempre juntas em viagens divertidas: Talisia. Ana Paula. Michele, Vanessa. Marcela, Olivia. Obrigada pela companheirisma.

À minha grande amiga Michele, a Mi, par fazer parte de minha vida. Obrigada por me acolher desde que chequei à 
Botucatu. Obrigada pelos ensinamentos de vida e por dividirmos alegrias e tristezas. Pela amizade sincera!!

Aos meus professores da USC. especialmente Eliane Stéfana, Karla Panice. Dulce Canstantina. Valéria Rameira, Daniela Nicaliela e Jasé Antânia Radriques (Zezita).

Meu eterna e especial abrigado à Siluana 7. Coradi que nãa me ensinou apenas as liçöes da sala de aula. Se enxerquei un caminho mais adiante, foi par que uacê me ajudau a encontrá-la!

Aos meus queridos amigos que conheci na épaca da faculdade: Carlos Henrique, Márcia, Claudia, Milca, Tiaga, Radriga, Sávia. Livia. Heloisa. Michele Furlanetta. Guilherme Bianda... Vacês sãa amigos pra vida toda! Eternos e especiais!

At minha querida famelia... tios e tias, primos e primas. Pelas alegrias!

ta CMPq. pela cancessãa da balsa de estudas e à FAPESP. pela auxilia financeira. 
"Cada pessoa que passa em nossa vida passa sozinha, pois cada pessoa é única e nenhuma substitui a outra. Cada pessoa que passa em nossa vida passa sozinha, mas nãa wai sá. nem nos deixa sá. Leva um panca de nós mesmas, deixa um panca de si. Essa é a mais bela responsabilidade da vida e a proua de que as pessoas nãa se encontram par acasa. 
Trabalko realizado no Departamenta de Patalogia da Faculdade de Medicina de Botucatu. UNESP. 
Sumária 
Sumário

Capítulo I .18

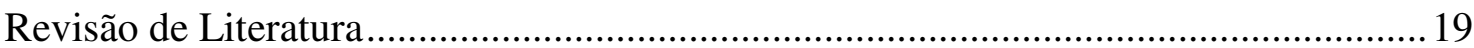

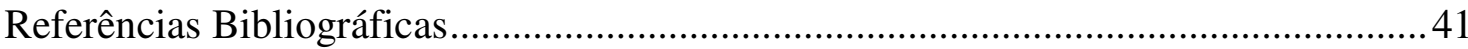

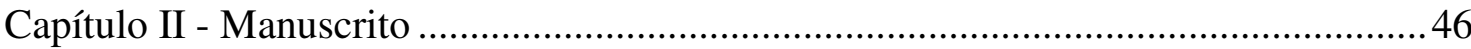

Perfil de citocinas inflamatórias em indivíduos submetidos a procedimentos

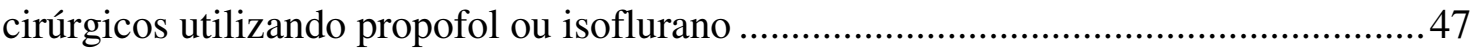

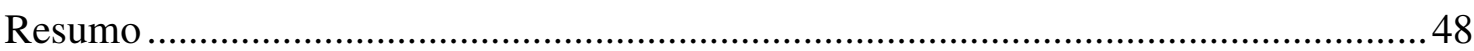

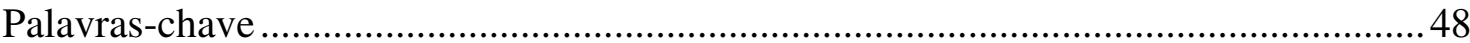

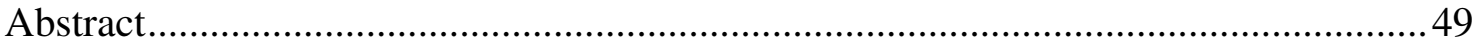

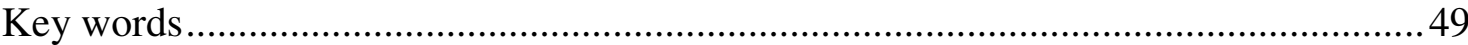

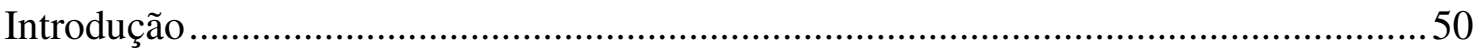

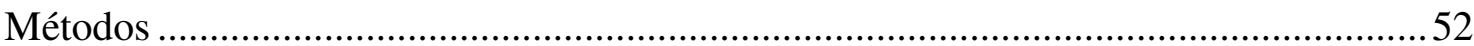

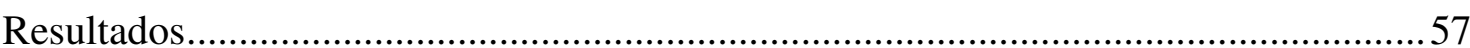

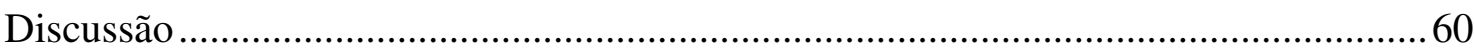

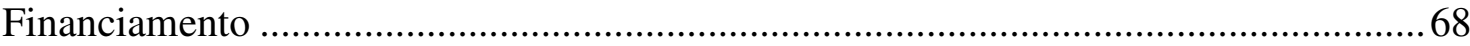

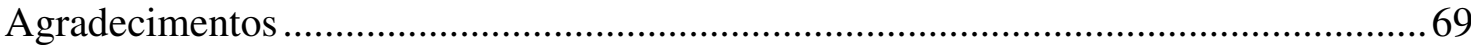

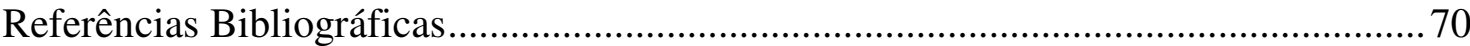

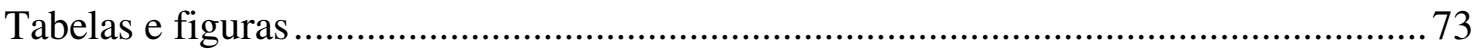

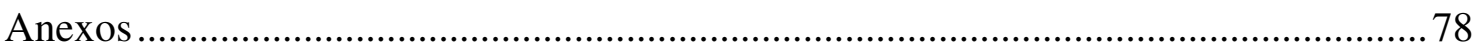

Anexo 1- Termo de Consentimento Livre e Esclarecido ................................................ 79

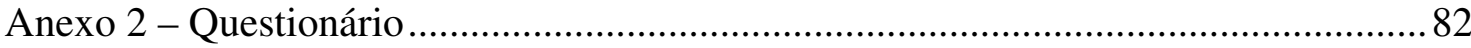

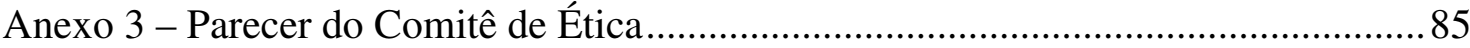


Capitula 01 
Revisãa de Literatura 
O trauma tecidual oriundo do procedimento cirúrgico provoca no paciente uma resposta conhecida como stress, a qual é influenciada pelo emprego de anestesia ${ }^{1}$. O stress envolve alterações fisiológicas importantes, tais como alterações endócrinas, metabólicas e hematológicas ${ }^{2}$, além de um processo inflamatório, necessário para promoção da homeostasia e reparo do tecido lesionado. Em pacientes saudáveis, esta resposta geralmente culmina em resolução tranquila do processo ${ }^{1}$.

O stress em resposta ao trauma anestésico-cirúrgico envolve uma fase inicial de hipometabolismo seguida por uma fase hipermetabólica. A fase hipometabólica, conhecida como choque, representa uma resposta direcionada à sobrevivência do paciente. É caracterizada por vasoconstrição periférica, hipotermia e direcionamento de sangue para órgãos vitais, resultando em diminuição do consumo total de energia. Mesmo pacientes saudáveis submetidos à cirurgia eletiva apresentam este quadro, o qual é necessário para assegurar que órgãos como coração e sistema nervoso central recebam nutrientes e energia ${ }^{1}$.

Após a primeira fase segue-se uma fase de hipermetabolismo, onde há aumento no consumo de energia. Na resposta inflamatória ao trauma ocorre o influxo de células para o local da agressão cirúrgica, a fim de reparar o tecido e promover a homeostasia ${ }^{3}$. Dentre as células envolvidas citam-se leucócitos, células endoteliais, fibroblastos e mastócitos. Para o desempenho de suas funções, estas células requerem suprimento contínuo de glicose e oxigênio para a respiração celular, caracterizando a fase hipermetabólica ${ }^{1,3}$. A vasodilatação, o aumento no fluxo sanguíneo e o aumento da permeabilidade vascular, necessários para distribuição de glicose e aminoácidos para o local da agressão, também caracterizam esta segunda fase ${ }^{1}$.

Para o desencadeamento e modulação da resposta inflamatória, células endoteliais vasculares, leucócitos, fibroblastos e mastócitos necessitam de mediadores 
inflamatórios, os quais promovem a comunicação entre células. Os mediadores agem de maneira coordenada e finamente regulada para influenciar a ampla variedade de atividades biológicas referentes ao processo inflamatório, tais como: adesão e agregação celular, quimiotaxia, sobrevivência e proliferação celular e coagulação. Entre estes mediadores encontram-se a histamina, os mediadores lipídicos, citocinas, proteínas de fase aguda, hormônios e aqueles mediadores pertencentes aos sistemas plasmáticos de coagulação, fibrinolítico, de cininas e complemento.

A histamina é um importante mediador aminovasoativo da resposta inflamatória aguda e das reações alérgicas, apresentando-se pré-formada e estocada em grânulos citoplasmáticos de basófilos e mastócitos ${ }^{4}$. A liberação de histamina por estas células ocorre quando há ativação de receptores para imunoglobulina (Ig) E ou pela ação de componentes do complemento e citocinas ${ }^{4,5}$. A histamina exerce suas funções através de quatro receptores: $\mathrm{H} 1, \mathrm{H} 2, \mathrm{H} 3$ e H4. As atividades pró-inflamatórias da histamina são mediadas pelo receptor $\mathrm{H} 1$, enquanto que o receptor $\mathrm{H} 2$ media as atividades antiinflamatórias e imunossupressoras e o receptor H3 regula a liberação de citocinas em macrófagos e mastócitos 5 .

Os quatro sistemas plasmáticos acima citados têm seus componentes ativados em cascata, ou seja, um precursor inicial, quando ativado, passa a ativar o componente seguinte deste sistema através da clivagem proteolítica, e assim sucessivamente, até que os produtos finais sejam ativados. As cascatas de coagulação, fibrinolítica e das cininas são ativadas pelo fator XIIa. Já a cascata do complemento pode ser ativada pelo complexo antígeno-anticorpo (via clássica) ou por substâncias derivadas de microrganismos como lipopolissacarídeos e toxinas (via alternativa) ${ }^{6}$.

O sistema complemento é formado por mais de trinta proteínas séricas e celulares que, após clivagem e ativação, formam o complexo de ataque à membrana. 
Este complexo promove a lise de antígenos e de células infectadas ${ }^{6}$. Cada componente clivado é responsável por uma ou mais funções no processo inflamatório. Os componentes C3a, C4a e C5a formados são anafilatoxinas, cujas funções incluem contração da musculatura lisa, alterações na permeabilidade vascular, liberação de histamina por mastócitos, quimiotaxia de leucócitos, ativação e agregação plaquetárias e regulação da expressão de moléculas de adesão ${ }^{6,7}$.

Uma das formas de ativação do processo de coagulação sanguínea é a agressão ao endotélio vascular, com a expressão de fatores teciduais e produção de fibrina ${ }^{8}$. A fibrina, produto final da cascata de coagulação, é formada pela ação da trombina sobre o fibrinogênio. Além desta função, a trombina aumenta a expressão de moléculas de adesão, promove a adesão de monócitos e neutrófilos e estimula a produção de fator ativador de plaquetas (PAF) ${ }^{8,9}$.

Durante o processo de fibrinólise as células endoteliais liberam o ativador de plasminogênio tecidual, culminando em ativação da plasmina, responsável por degradar a fibrina e, dessa forma, dissolver o coágulo ${ }^{8,10}$. A dissolução do coágulo de fibrina é importante para manter a homeostasia e permeabilidade vascular e para facilitar a migração celular ${ }^{10}$.

O sistema de cininas é composto por pró-calicreínas, calicreínas tecidual e plasmática, cininogênios, cininas, cininases e enzimas conversoras de cininas ${ }^{11}$. A bradicinina, produzida a partir do cininogênio pela ação das calicreínas, tem como funções o controle do tônus vascular, a promoção da vasodilatação através da liberação de óxido nítrico e o estímulo da produção de eicosanóides pela ativação da fosfolipase $\mathrm{A}_{2}$ (PLA2) ${ }^{11,12}$.

Entre os mediadores lipídicos pode-se citar prostaglandinas, leucotrienos, lipoxinas, fator ativador de plaquetas, entre outros. São sintetizados conforme a 
necessidade do organismo a partir de precursores lipídicos, presentes na membrana celular, sendo convertidos a ácido araquidônico e a lisofosfolipídios pela ação da PLA 2 13,14

As vias da cicloxigenase e a da lipoxigenase são caminhos pelos quais ocorre a síntese de alguns mediadores lipídicos. A enzima cicloxigenase (COX), cujas isoenzimas são COX-1 e COX-2, catalisa a incorporação de moléculas de oxigênio ao ácido araquidônico, culminando na síntese de vários tipos de prostaglandinas ${ }^{15,16}$. A 5lipoxigenase, uma das seis enzimas existentes, produz leucotrieno (LT) A4, o qual é convertido a LTB4 ou a cisteinil-LT ${ }^{17}$.

Além destes mediadores, outros agora estão sendo descritos como produtos da via da lipoxigenase, dentre eles as lipoxinas, resolvinas e protectinas. Estes três últimos têm atividades anti-inflamatória e de pró-resolução da inflamação ${ }^{18}$.

Ainda, o PAF é um fosfolipídio de membrana sintetizado a partir de glicerofosfolipídios de membrana celular pela ação da PLA2. Inicialmente, o PAF foi caracterizado apenas como agente hipotensor e mediador da ativação plaquetária ${ }^{13}$. Entretanto, ele possui diferentes atividades biológicas na maioria dos tecidos, como, por exemplo, promoção da broncoconstrição ${ }^{9}$.

Por fim, as citocinas compreendem um grupo de polipeptídeos que agem como mensageiros autócrinos, parácrinos e endócrinos, formando uma complexa rede de comunicação entre as células ${ }^{19,20}$. Através desta rede, as citocinas determinam a resposta inflamatória a diferentes estímulos e promovem sinais que determinam o desencadeamento da resposta imune adaptativa ao antígeno ${ }^{20}$. Em quadros infecciosos, elas podem elevar a temperatura corpórea, o que pode ser deletério para crescimento de organismos invasores. Na resposta inflamatória aguda, elas agem sobre o fígado, estimulando a liberação de proteínas de fase aguda, as quais ativam o sistema 
complemento e a fagocitose ${ }^{21}$. Ainda, alteram a permeabilidade dos vasos sanguíneos, promovem recrutamento de células fagocitárias e moléculas mediadoras para o local da agressão e regulam a expressão e a síntese de várias proteínas envolvidas nos processos de coagulação e fibrinólise ${ }^{9}$.

As citocinas, portanto, promovem a modulação da resposta inflamatória desde seus eventos iniciais até sua resolução. Sendo assim, há dois grupos de citocinas inflamatórias, a saber: as pró-inflamatórias e as anti-inflamatórias.

Entre as citocinas pró-inflamatórias podem-se citar as interleucinas (IL) IL-1 $\beta$, IL-6, IL-8, IL-12 e o fator de necrose tumoral alfa (TNF- $\alpha)$.

A IL-6 tem grande importância em quadros de stress relacionado a procedimentos anestésico-cirúrgicos ${ }^{2,19}$. Após o estímulo, é sintetizada por células endoteliais, fibroblastos, tecido adiposo e, principalmente, macrófagos, monócitos e linfócitos TH2 ${ }^{22}$. Muitas funções biológicas da IL-6 são também desempenhadas por IL-1 e TNF- $\alpha$. Na resposta de fase aguda, a IL-6 é a citocina com maior poder de induzir a síntese de proteínas de fase aguda pelos hepatócitos, sendo que a IL-1 e o TNF- $\alpha$ apresentam fraco efeito sobre a síntese das mesmas proteínas ${ }^{22}$. Em sinergismo, a IL-1 e a IL-6 promovem a ativação e proliferação de linfócitos T. A IL-6 induz fracamente a elevação da temperatura corpórea, induz a diferenciação de linfócitos B em plasmócitos e a liberação de $\operatorname{IgM}, \operatorname{IgG}$ e $\operatorname{Ig} \mathrm{A}$ e estimula a proliferação de células germinativas hematopoéticas ${ }^{19,22}$. Ainda, juntamente com IL-1 $\beta$ e TNF- $\alpha$, a IL-6 atua sobre o eixo hipotalâmico-pituitário-adrenal (HPA), interligando os sistemas nervoso, endócrino e imunológico ${ }^{19,23}$.

A IL-1, outro mediador da resposta inflamatória, pode ser produzida por todas as células nucleadas. O LTB4 estimula a síntese de IL-1, cabendo às prostaglandina E2 e resolvina D1 a função de inibir a síntese desta citocina ${ }^{18}$. A IL-1 $\beta$ derivada de plaquetas 
é considerada um dos principais mediadores da ativação de células endoteliais, estimulando a síntese de moléculas essenciais para pavimentação leucocitária nos vasos sanguíneos ${ }^{24,25}$. Esta citocina também promove aumento na geração de óxido nítrico (NO) em casos de sepse, favorecendo a venodilatação, característica deste quadro clínico ${ }^{26}$. Ainda, a secreção de IL-6 e IL-8 por células endoteliais é induzida pela IL-1 após sua ativação por plaquetas ${ }^{25}$. A liberação aumentada de citocinas e a regulação de moléculas de adesão endotelial através da IL-1 $\beta$ ocorrem para promover a adesão de monócitos e neutrófilos ao endotélio ${ }^{24}$.

A IL-1 e o TNF- $\alpha$ atuam em sinergismo. Agindo sozinha, a IL-1 não induz lesão ao tecido ou apoptose durante resposta de fase aguda, mas potencializa os efeitos do $\mathrm{TNF}-\alpha^{19}$

O TNF pertence a uma grande família de citocinas, composta por mais de 40 membros, que inclui, além do referido TNF, ampla gama de receptores como FAS e receptores para TNF I e II (TNFRI e TNFRII) ${ }^{27}$. O TNF atua efetivamente em processos infecciosos causados por Mycobacterium tuberculosis, Mycobacterium avium, Leishmania major e Trypanossoma cruzi, entre outros, apresentando função protetora contra bactérias e parasitas intracelulares através da ativação de macrófagos e da produção de óxido nítrico ${ }^{28-30}$. Por sua participação em processos de proliferação, sobrevivência, diferenciação e apoptose em células responsivas, os membros da família TNF/TNFR são utilizados atualmente como alvos para terapia em doenças autoimunes, osteoporose e câncer $^{27}$.

O TNF apresenta-se nas formas $\alpha$ e $\beta$. O TNF- $\alpha$ é produzido por macrófagos, células endoteliais, fibroblastos e linfócitos $\mathrm{T}$ e $\mathrm{B}$ minutos após a injúria local ou sistêmica. Portanto, o TNF tem papel central no desencadeamento de processos 
inflamatórios, sendo um dos mediadores mais importantes no início destes processos ${ }^{18}$, 27.

Juntos, a IL-1 $\beta$ e o TNF- $\alpha$ são peça-chave para ativação das cascatas do sistema plasmático logo no início do processo inflamatório, apresentando potencial para afetar a ampla rede de mecanismos biológicos deste processo ${ }^{31}$. Ainda no início do processo inflamatório, agem de formas autócrina e parácrina na indução da síntese das citocinas IL-6 e IL-8 ${ }^{18,}{ }^{32}$. Também possuem as funções de ativar metabolismo de neutrófilos, macrófagos e fibroblastos, estimular angiogênese, estimular lipólise em quadros de infecção crônica, induzir expressão de fatores teciduais no endotélio vascular e mediar o processo de reparo tecidual ${ }^{9}$. O TNF- $\alpha$ estimula síntese de moléculas de adesão endotelial, modula cascata do complemento, modula a ativação da cascata de coagulação, através da regulação da expressão da proteína $\mathrm{C}$ ativada, além de ser pirógeno endógeno ${ }^{9,33}$.

A IL-8 é sintetizada por macrófagos, monócitos, linfócitos T, fibroblastos e células endoteliais. Por sua vez, a inibição da expressão gênica de IL-8 em neutrófilos é promovida pelas lipoxinas ${ }^{34}$. A IL-8 tem papel chave na inflamação por promover a quimiotaxia de neutrófilos, basófilos e linfócitos T e regular a explosão respiratória e a diapedese de neutrófilos ${ }^{19,35}$.

A IL-12 é uma importante citocina pró-inflamatória produzida por células dendríticas, macrófagos e linfócitos TH1. Nesta última célula, a liberação de IL-12 pode induzir a síntese de IL-10 ${ }^{36}$. A IL-12 direciona a resposta imunológica para o perfil TH1.

A atividade das citocinas pró-inflamatórias é regulada pelas citocinas antiinflamatórias. Dentre elas, pode-se citar a IL-10, o fator transformador de crescimento (TGF)- $\beta$, o antagonista de receptor para IL-1 (IL-1ra) e os receptores TNFRI e TNFRII. 
A IL-10 é uma importante citocina anti-inflamatória pela sua capacidade de inibir a produção de citocinas pró-inflamatórias em macrófagos, monócitos e células dendríticas ${ }^{37-39}$. Por exemplo, a IL-10 é potente inibidora da produção e liberação de TNF- $\alpha$, IL-1 $\beta$, IL-6, IL-8 e IL-12 19, 40 . A inibição da síntese de TNF por macrófagos, provocado pela IL-10, limita a habilidade destas células para matar organismos intracelulares ${ }^{39}$. A ação da IL-10 sobre citocinas pró-inflamatórias não consiste em apenas inibir a sua liberação, mas também em inibir as atividades biológicas de citocinas como IL-2, TNF- $\alpha$, IL-4 e interferon- $\gamma($ IFN- $\gamma)$.

Um dos mecanismos inicialmente propostos para inibição da síntese de citocinas por IL-10 levava em consideração o fato de linfócitos TH2 liberarem IL-10 quando ativados pelas células apresentadoras de antígeno (APC), o que inibiria a produção de IL-2, TNF- $\alpha$, IFN- $\gamma$ e GM-CSF por linfócitos TH1 ${ }^{41}$. Hoje sabe-se que a IL-10 é produzida não somente por linfócitos TH2, mas também por linfócitos $\mathrm{B}$, mastócitos, eosinófilos, macrófagos, células dendríticas, linfócitos T regulatórios (linfócitos T REG), linfócitos T CD4+ e linfócitos T CD8+ ${ }^{36,38}$. Quanto à produção de IL-10 por linfócitos TH1, ela pode moderar ou inibir a resposta inflamatória, impedindo, por exemplo, a recuperação de lesões por Leishmania ${ }^{42}$.

A atividade imunossupressora da IL-10 desenvolve-se através de um mecanismo de retroalimentação a fim de controlar quadros de infecções não oportunistas ${ }^{36,} 39$. Assim, os níveis desta citocina podem ser cruciais para determinar se, por exemplo, num quadro de leishmaniose, haverá eliminação do patógeno ou se haverá desenvolvimento de um quadro infeccioso persistente ${ }^{36}$.

A inibição da síntese de citocinas por IL-10 e a modulação de mecanismos imunológicos por esta citocina também podem ser verificadas pela sua capacidade em regular a expressão de moléculas do complexo de histocompatibilidade principal de 
classe II (MHC cl II) por macrófagos e células dendríticas ${ }^{37,39}$, ao inibir sua capacidade de apresentação de antígenos. Outros mecanismos moduladores de IL-10 incluem bloqueio da expressão de moléculas coestimulatórias como CD80 e CD86 ${ }^{39}$, modificação da expressão de receptores para quimiocinas ${ }^{43,44}$ e aumento da geração de radicais ${ }^{45}$.

A IL-10 também inibe a maturação de células dendríticas a partir dos precursores de monócitos ${ }^{46}$. Por inibir a produção de citocinas pró-inflamatórias por estas células e por macrófagos, IL-10 tem efeito sobre a supressão da resposta celular promovida por $\mathrm{TH}{ }^{36}$. Além desta função imunossupressora, IL-10 promove estimulação de mastócitos, favorece a diferenciação e migração de linfócitos $\mathrm{T}$ citotóxicos e ativa a produção de $\operatorname{Ig}$ A por linfócitos $\mathrm{B}^{36}$.

Outras atividades biológicas da IL-10 incluem a promoção do desenvolvimento e sobrevivência de linfócitos $\mathrm{B}$ e a indução da sobrevivência de linfócitos $\mathrm{T}$ e, até mesmo, de células tumorais ${ }^{38}$. Paradoxalmente, a IL-10 pode induzir a apoptose de células B leucêmicas em leucemias linfóides crônicas ${ }^{47}$.

Finalmente, por suas muitas atividades biológicas, especialmente por sua propriedade anti-inflamatória, a IL-10 pode limitar a magnitude das respostas inflamatória e imune.

Como se pode observar, uma mesma atividade biológica é desempenhada pela interação entre várias citocinas e células, bem como uma mesma citocina apresenta várias funções. Isso explica a ação de forma integrada das citocinas e sua importância como elo entre os diferentes sistemas fisiológicos.

A integração entre todos os sistemas e mediadores permite a elaboração e desenvolvimento de uma resposta inflamatória adequada para o restabelecimento da homeostase do organismo do paciente submetido ao procedimento anestésico-cirúrgico. 
Essa resposta é importante para a evolução do quadro do paciente, já que promove cicatrização e reparo dos tecidos lesionados durante a cirurgia ${ }^{2}$. Entretanto, uma resposta inflamatória excessiva pode contribuir para o agravamento do quadro clínico nos períodos peri e pós-operatório ${ }^{48}$. Dentre as complicações citam-se síndrome respiratória inflamatória sistêmica (SIRS), distúrbios na cicatrização de feridas, sepse, síndrome da resposta anti-inflamatória compensatória (CARS), disfunção múltipla de órgãos (MOD) e morte ${ }^{19}$.

No quadro de SIRS, a cascata inflamatória originada a partir da lesão tecidual pode levar à ativação exacerbada do sistema imunológico e liberação de hormônios glicocorticóides, catecolaminas e citocinas pró-inflamatórias (TNF- $\alpha$, IL-1 e IL-6) ${ }^{19}$. A produção de citocinas pró-inflamatórias neste quadro clínico é exagerada e, juntamente com a liberação de outros mediadores, pode levar à alteração no endotélio vascular e indução de forma exacerbada da cascata de coagulação, levando à hipotensão, perfusão inadequada dos órgãos e apoptose associada à MOD ${ }^{19}$. Situação oposta ocorre no quadro clínico de CARS, onde as citocinas inflamatórias e mediadores liberados contribuem para imunossupressão inapropriada, com liberação exagerada de citocinas anti-inflamatórias ${ }^{19}$. Há, neste caso, baixa responsividade de linfócitos $\mathrm{T}$, anergia, diminuição de apresentação de antígeno e da proliferação de linfócitos T, bem como alta taxa de apoptose em linfócitos T e $\mathrm{B}^{19}$.

A evolução do quadro clínico do paciente submetido à cirurgia para SIRS ou CARS torna-o susceptível a infecções secundárias, o que muitas vezes pode levá-lo a óbito. A imunossupressão observada nesses casos é reflexo da mudança do perfil TH1 para $\mathrm{TH} 2$ de forma mais pronunciada daquela ocorrida em uma resposta inflamatória normal ${ }^{1}$. Cabe frisar, entretanto, que a resposta inflamatória dentro dos parâmetros de normalidade torna-se necessária para recuperação deste paciente e promoção da 
homeostasia. A evolução do quadro do paciente no período peri-operatório então, pode ser direcionada para rápida recuperação ou para um quadro patológico, por exemplo, de sepse, dependendo do grau e da duração da resposta inflamatória neste período ${ }^{49}$. A resposta inflamatória, por sua vez, pode ser influenciada pelo trauma tecidual oriundo da incisão cirúrgica, pelas variações biológicas individuais e pela anestesia empregada $19,35,48,50$.

Com relação às variáveis biológicas devem ser considerados o sexo do paciente, sua idade e suas características genéticas. Com relação ao sexo, hormônios esteróides e corticosteróides influenciam eventuais respostas imunológicas. Por exemplo, cortisol, progesterona e estrógeno modulam o balanço dos perfis TH1/TH2 em mulheres que apresentam doenças auto-imunes, como artrite reumatóide e lúpus eritematoso sistêmico 51.

A gravidade da cirurgia e o trauma tecidual originado são fatores importantes que devem ser levados em consideração na análise da recuperação do paciente. Com relação à anestesia, a técnica anestésica e o anestésico empregado têm influência sobre a resposta do indivíduo submetido a este procedimento. Desta forma, devem ser observados atentamente o emprego de anestesia local ou geral, o emprego de anestésico volátil ou intravenoso e a classe do fármaco empregado nesta anestesia ${ }^{19}$.

Frente à cirurgia ocorre a liberação de citocinas inflamatórias na corrente sanguínea, a qual é fator relevante para o desencadeamento e coordenação do stress em resposta ao procedimento anestésico-cirúrgico ${ }^{2,35,50}$. Logo após a incisão da pele são liberadas as citocinas pró-inflamatórias IL-1 $\beta$ e TNF- $\alpha{ }^{19}$. Em seguida, IL-6 e, posteriormente, IL-8 são liberadas ${ }^{19,49}$. A IL-10, sendo uma citocina anti-inflamatória, regula a liberação das citocinas pró-inflamatórias ${ }^{37,52}$. 
As citocinas pró-inflamatórias ativam o eixo hipotalâmico-pituitário-adrenal (HPA), resultando em fluxo de hormônios e neurotransmissores durante o stress. Desta forma, este eixo, ao ser ativado, e o sistema nervoso autonômico, liberam hormônios como o adrenocorticotrófico (ACTH) e o cortisol, e neurotransmissores como as catecolaminas (noraepinefrina e epinefrina) ${ }^{23}$. Monócitos, macrófagos e linfócitos $\mathrm{T}$ possuem receptores para estes hormônios e, por isso, promovem a sinalização celular para a produção de citocinas anti-inflamatórias como IL-4 e IL-10, as quais podem direcionar uma resposta para o perfil $\mathrm{TH} 2{ }^{40,53}$. Assim, a produção de citocinas como IL-12 e IFN- $\gamma$, que direcionam a resposta para o perfil TH1, é inibida também pelo hormônio ACTH e pelas catecolaminas ${ }^{40,54}$. As citocinas anti-inflamatórias liberadas impedem uma resposta inflamatória exagerada ao procedimento anestésico-cirúrgico ${ }^{23}$. Desta forma, logo no início deste procedimento há uma resposta iniciada pela produção de citocinas pró-inflamatórias, enquanto que as anti-inflamatórias são liberadas posteriormente a fim limitar a duração e a gravidade das ações das primeiras. Só então é que ocorre a resolução da resposta inflamatória. Sendo assim, a liberação de citocinas inflamatórias pode ser apenas transitória em indivíduos saudáveis ${ }^{19}$ ou exagerada e persistente em quadros evoluídos para complicações ${ }^{48,49}$.

Os eventos neuro-endocrino-hormonais são diretamente proporcionais ao dano tecidual causado pelo procedimento anestésico-cirúrgico ${ }^{2,48}$. Assim sendo, cirurgia de pequeno porte traz alterações menores, ou de curta-duração, em relação às cirurgias de grande porte.

Um exemplo pode ser citado através da comparação entre técnicas cirúrgicas abdominais minimamente invasivas (como laparoscopia) e cirurgia abdominal aberta, onde o primeiro tipo mostrou redução da resposta inflamatória, incluindo síntese de proteínas de fase aguda, leucocitose, produção de IL-6 e hipercoagulação ${ }^{54,} 55$. 
Também, cirurgias cardíacas sem circulação extra-corpórea (CEC) diminuíram a concentração das citocinas TNF- $\alpha$, IL-6, IL-8, IL-10, TNFRI e TNFRII, em relação à cirurgia cardíaca empregando $\mathrm{CEC}^{56,57}$.

Exemplificando cirurgia de grande porte, pode-se citar um estudo com pacientes submetidos à neurocirurgia, os quais apresentaram concentrações aumentadas de IL-10 40. Neste quadro de imunossupressão, ocorrida graças à liberação de IL-10, não foi observada qualquer sinal de inflamação sistêmica, como concentrações plasmáticos de TNF- $\alpha$ ou IL- ${ }^{40}$. Este estudo, portanto, pode exemplificar de forma fiel o efeito do trauma cirúrgico importante sobre a resposta inflamatória.

A IL-6 é a principal citocina inflamatória circulante ${ }^{2}$ e sua liberação durante quadros de stress em resposta ao procedimento anestésico-cirúrgico tem se tornado alvo de pesquisas na atualidade. Estudos têm relacionado aumento persistente nas concentrações desta citocina com grupos de pacientes internados em unidade de terapia intensiva com síndrome do stress respiratório em adultos (ARDS) ou em quadros de sepse severa ${ }^{49,58}$. Desta forma, a IL-6 pode ser considerada marcador para a resposta inflamatória em andamento ${ }^{19,49,58}$.

A ARDS, vale lembrar, é um quadro clínico caracterizado por lesão aguda e difusa das superfícies endoteliais e epiteliais pulmonares, levando à falência respiratória 49. Já a sepse é uma resposta sistêmica a um quadro infeccioso, onde há elevada liberação de citocinas anti e pró-inflamatórias ${ }^{59}$.

A IL-1 $\beta$ também pode ser considerada eficiente preditor da evolução do quadro de pacientes com ARDS, sendo que valores altos desta citocina representam prognóstico de morte, independente de sepse ou choque ${ }^{49}$. Nestes pacientes, a concentração plasmática de TNF- $\alpha$ está também relacionada com gravidade e mortalidade ${ }^{49}$. 
Valores aumentados de TNF em processos inflamatórios, caracterizando uma ação incontrolada das potentes atividades biológicas dessa citocina, poderiam levar a um quadro de endotoxicidade sistêmica, caracterizado por febre, hipotensão e choque ${ }^{27}$. Esse quadro clínico seria, portanto, fruto de resposta inflamatória exacerbada a um determinado trauma, por exemplo, um procedimento cirúrgico de grande complexidade. Essa situação, bem como casos de sepse, ARDS e SIRS, seria diferente, com relação à gravidade, daquele stress observado em resposta a procedimentos anestésico-cirúrgicos em indivíduos saudáveis. Nestes indivíduos saudáveis, ou mesmo naqueles com algum problema de saúde, mas que seu quadro clínico não evoluiu para complicações póscirúrgicas, o objetivo da resposta inflamatória, que é o de promover a homeostasia através da cicatrização do tecido e reparação do dano, foi alcançado. Em suma, o controle do processo inflamatório, através do perfil de liberação de citocinas inflamatórias, é o fator que pode definir a evolução do quadro do paciente submetido a procedimento anestésico-cirúrgico à rápida melhora ou a um quadro grave como SIRS ou CARS.

Dessa forma, o perfil de cada citocina inflamatória deve ser analisado com cautela em cada situação de procedimento anestésico-cirúrgico, já que concentrações aumentadas apenas de forma transitória podem ser observados em pacientes sadios submetidos a esse procedimento ${ }^{19}$. Como já dito, além das características individuais do paciente, a técnica anestésica e o anestésico empregado também têm efeito modulador sobre a resposta inflamatória a esse tipo de procedimento.

Com relação à técnica anestésica, há dois tipos que podem ser empregados, a saber, a anestesia local e a anestesia geral.

Os anestésicos locais agem através do bloqueio na condução dos impulsos nos nervos sensoriais periféricos, ao contrário dos anestésicos gerais, que agem diretamente 
sobre o sistema nervoso central ${ }^{60}$. Desta forma, sob anestesia geral o paciente torna-se inconsciente do, e não-responsivo ao, estímulo doloroso ${ }^{60}$.

Ao nível celular, o efeito dos anestésicos consiste em inibir a transmissão sináptica através da redução da liberação do transmissor, inibição da ação do transmissor ou redução da excitabilidade da célula pós-sináptica ${ }^{60}$. Little ${ }^{61}$ explica que a ação das sinapses inibitórias pode ser aumentada ou diminuída pelos anestésicos. Exemplificando, os barbituratos e alguns anestésicos voláteis aumentam a ação dessas sinapses ${ }^{61}$. Entretanto, não é possível identificar um local-alvo crítico no cérebro que seja responsável por todos os fenômenos da anestesia, já que, quando em altas concentrações, os anestésicos afetam todas as funções cerebrais, desde o controle motor até a regulação da respiração ${ }^{60}$.

Considera-se que a anestesia geral é supressora da imunidade por afetar diretamente o sistema imunológico ou por ativar o eixo HPA e sistema nervoso simpático ${ }^{23}$. O sistema imune é afetado pelo anestésico empregado nas funções das células imunes e na expressão gênica e secreção de mediadores inflamatórios como as citocinas $34,23,50$.

Com relação ao anestésico geral empregado, deve-se observar atentamente as características de cada anestésico. Para ser empregado como tal, o anestésico deve ser prontamente controlável, de modo que a indução e a recuperação sejam rápidas, permitindo que o nível de anestesia seja controlado conforme necessário durante o procedimento cirúrgico ${ }^{60}$. Anestésicos gerais podem ser empregados de forma inalatória ou intravenosa.

Os anestésicos empregados por via inalatória, chamados anestésicos voláteis, pertencem a diferentes classes químicas, sendo inalados e excretados pelos pulmões. Como a degradação metabólica do anestésico é importante em determinar a duração de 
sua ação, é a velocidade da liberação do fármaco aos e dos pulmões que determina o comportamento cinético desse anestésico ${ }^{60}$.

Dentre aqueles anestésicos empregados pela via inalatória um dos mais utilizados atualmente é o isoflurano.

O isoflurano é um anestésico halogenado que pode apresentar média velocidade de indução e recuperação anestésicas, não apresentando o cheiro adocicado de outros halogenados, como sevoflurano ou desflurano. Provoca poucos efeitos adversos e é pouco metabolizado pelo organismo, apresentando pequeno sinal de toxicidade. Entre seus efeitos orgânicos, tende a causar hipotensão e é potente vasodilatador coronariano 60.

Muitos estudos in vivo e in vitro têm sido realizados com isoflurano para verificar a influência deste anestésico na resposta inflamatória pulmonar. Estudo in vitro com cultura primária de células alveolares de camundongos, desafiadas com anestésicos voláteis ${ }^{62}$, mostrou diminuição transitória na liberação de citocinas inflamatórias, principalmente IL-6, por estas células. Estes dados são conflitantes com estudo ${ }^{63}$ que mostra a indução da expressão gênica de citocinas pró-inflamatórias após inalação de anestésicos voláteis por camundongos, o que poderia indicar aumento na liberação destes mediadores em indivíduos sob anestesia por via inalatória.

O efeito inibitório dos anestésicos voláteis na liberação de citocinas inflamatórias também foi observado em estudos com células mononucleares do sangue periférico humano (PBMC) ${ }^{64,65}$. Nestes estudos, isoflurano suprimiu especificamente a liberação de IL-1 $\beta$ e TNF- $\alpha$ por linfócitos e células natural killer. Com a inibição das citocinas pró-inflamatórias, o anestésico volátil poderia contribuir para uma resposta anti-inflamatória, o que seria benéfico em situações como a de SIRS. 
Além dos trabalhos in vitro e com animais, estudos envolvendo pacientes submetidos à cirurgia com isoflurano também têm sido realizados. Como exemplo, estudo envolvendo pacientes submetidos à cirurgia abdominal sob anestesia com isoflurano revelou aumento significativo nas concentrações plasmáticas de IL-6 durante e após a cirurgia ${ }^{66}$. Em outro estudo envolvendo as mesmas condições, pacientes apresentaram não apenas valores aumentados de IL-6 e TNF- $\alpha$ após cirurgia, mas também de IL-10, após a cirurgia, quando comparados com valores pré-cirúrgicos ${ }^{67}$. O aumento nos valores de IL-6, bem como de IL-8, durante e até 24 horas após cirurgia cardíaca, em pacientes sob anestesia volátil, também foi observado por El Azab et al ${ }^{50}$. A expressão gênica de citocinas pró-inflamatórias também foi aumentada em pacientes sob anestesia com isoflurano, indicando que a reação inflamatória é induzida a nível de transcrição dentro de poucas horas após a indução de anestesia ${ }^{35}$.

Como já dito anteriormente, os anestésicos podem ser empregados de forma inalatória ou intravenosa. Os anestésicos intravenosos atuam muito mais rapidamente do que os inalatórios, produzindo inconsciência dentro de poucos segundos, tão logo o fármaco atinja o cérebro ${ }^{60}$.

Entre estes anestésicos gerais, um dos mais empregados na prática médica atualmente é o propofol.

O propofol é rapidamente metabolizado pelo organismo, proporcionando recuperação rápida e não produzindo efeito de ressaca. Entre seus efeitos orgânicos, provoca depressão cardiovascular e respiratória ${ }^{60}$. Este é um anestésico pertencente ao grupo hidroxil-fenólico e tem semelhança com o antioxidante $\alpha$-tocoferol ${ }^{68}$. Ainda, o propofol não tem a tendência de causar movimentos involuntários e supressão adrenocortical $^{60}$. 
A liberação de IL-8 por neutrófilos em cultura, estimulados por lipopolissacarídeo (LPS), foi estudada por Galley et al ${ }^{69}$, o qual mostrou que células expostas ao propofol liberaram maior quantidade de IL-8 em comparação com aquelas não expostas ao anestésico. Entretanto, os níveis de mRNA para IL-8 continuaram elevados em ambos os grupos, sugerindo que o propofol altera a liberação, mas não a síntese de citocinas pró-inflamatórias. Outras citocinas pró-inflamatórias, como TNF- $\alpha$, IL-1 $\beta$ e IL-6 também apresentaram liberação e produção diminuídas pelo propofol em macrófagos ativados por LPS ${ }^{70}$. Entretanto, os dados com relação à TNF- $\alpha$ e IL-1 $\beta$ são conflitantes, já que também foi relatado aumento nos níveis destas citocinas em monócitos humanos, questionando, inclusive, se foi o anestésico quem estimulou a produção destes mediadores ${ }^{65}$. Com relação a esta dúvida, sugere-se que o efeito antiinflamatório do propofol pode não ser atribuído ao anestésico em si, mas sim ao seu veículo, que tem característica lipídica ${ }^{70}$.

Ainda com relação à liberação de citocinas pela ação do propofol, o balanço do perfil TH1/TH2 foi aumentado em PBMC humano, onde foram mensurados as concentrações de IFN- $\gamma$ (produzido por linfócitos TH1) e IL-4 (produzida por linfócitos TH2). Desta forma, propofol contribuiu para a manutenção da imunidade celular em pacientes imunocomprometidos ${ }^{72}$. Adicionalmente a estes resultados, outro estudo com linfócitos T sugere que propofol não inibe a ativação do fator nuclear kappa B (NF-kB), um fator de transcrição relacionado com expressão de genes para IFN- $\gamma$, IL-2, IL-6 e IL$8^{73}$. Já com relação à expressão gênica do NF-kB em macrófagos, houve aumento da expressão de citocinas pró-inflamatórias em pacientes sob procedimento cirúrgico com o mesmo anestésico ${ }^{35}$. Todos estes dados estão de acordo com trabalho de Larsen et al ${ }^{74}$, onde propofol não prejudicou a liberação de citocinas inflamatórias em resposta a endotoxina em hemocultura. 
O perfil de citocinas inflamatórias, ainda, foi estudado por El Azab e colaboradores ${ }^{50}$ em cirurgia cardíaca em pacientes submetidos à anestesia com propofol. Em seus resultados, encontrou valores aumentados de TNF- $\alpha$, IL-6 e IL-8 imediatamente após o início da cirurgia, apresentando valores máximos em 2 horas após o final da cirurgia. Os mesmos autores afirmam que este perfil de liberação de citocinas foi atribuído ao stress em resposta ao procedimento cirúrgico. Ainda com relação às cirurgias abertas, outro estudo envolvendo pacientes anestesiados com propofol mostrou aumento nas concentrações de IL-6 e TNF- $\alpha$ após final da cirurgia, em comparação com momento pré-cirúrgicos, além de mostrar aumento na concentração da citocina antiinflamatória IL-10 sob mesmas comparações ${ }^{67}$.

Como dito anteriormente, o perfil de citocinas inflamatórias liberadas em resposta ao procedimento anestésico-cirúrgico depende, entre outros fatores, da técnica anestésica empregada. Dessa forma, pode-se não apenas fazer um balanço entre citocinas pró e anti-inflamatórias frente a determinado anestésico, mas também fazer uma relação entre os anestésicos. Assim, podem ser feitas comparações de liberação de citocinas entre as várias técnicas anestésicas empregadas, a fim de verificar qual anestésico poderia induzir um perfil de liberação mais seguro para o paciente submetido à cirurgia. Nesta linha de raciocínio, poderiam ser comparados os perfis de liberação de citocinas inflamatórias em pacientes anestesiados com propofol ou isoflurano.

Como exemplo da influência do anestésico sobre a liberação de citocinas inflamatórias, El Azab et al ${ }^{50}$ encontraram valores de IL-6 maiores no grupo de pacientes que recebeu anestésico volátil, em comparação com grupo que recebeu propofol, após indução da anestesia e antes do início da cirurgia. Resultados semelhantes foram encontrados por Crozier et al ${ }^{66}$, onde houve retardo na liberação de IL-6 e diminuição da magnitude da resposta desta citocina em cirurgia abdominal sob 
anestesia com propofol, em comparação com anestesia com isoflurano. Estes dados podem ser confirmados ainda pro trabalho de Ke e colaboradores ${ }^{67}$, onde não apenas IL-6, mas também TNF- $\alpha$, apresentaram concentrações plasmáticas maiores em pacientes anestesiados com isoflurano, em comparação com propofol. Finalmente, trabalho comparando a expressão gênica de citocinas pró-inflamatórias mostrou aumento de sua expressão durante anestesia com isoflurano em relação à anestesia com propofol, sendo este resultado dependente do tempo e da duração da anestesia ${ }^{35}$.

Estes dados comprovam que a escolha do anestésico e da técnica anestésica pode afetar a resposta de citocinas inflamatórias em resposta à cirurgia.

A partir do exposto, pode-se observar a importância das citocinas inflamatórias na coordenação do stress frente ao trauma anestésico-cirúrgico. Observa-se ainda a importância da técnica e do próprio anestésico em influenciar esta resposta e como esta pode afetar a recuperação do paciente no período peri-operatório.

Diante deste quadro, verifica-se a necessidade de estudos para caracterizar de forma precisa a relação entre stress e evolução do período peri-operatório em pacientes submetidos a procedimentos anestésico-cirúrgicos. Com estes estudos, poderia haver maior número de parâmetros para facilitar o reconhecimento de desvios na evolução normal da resposta inflamatória e, assim, evitar ou intervir de forma rápida em casos de imunossupressão ou resposta exacerbada nesses pacientes. Os resultados encontrados nesta linha poderiam sugerir, futuramente, a utilização da quantificação de citocinas para predizer a recuperação dos referidos pacientes. Ainda, estes estudos poderiam auxiliar equipe médica na escolha do anestésico e da técnica anestésica mais adequados para cada paciente.

Ainda, observa-se que os dados encontrados na literatura são, em sua maioria, relacionados com estudos in vitro, com animais de experimentação ou com pacientes 
submetidos à cirurgia de grande porte como neurocirurgias, cirurgias cardíacas e de colecistectomia $^{40,50,67}$. Até o momento, há poucos relatos sobre o efeito de diferentes anestésicos na liberação de citocinas inflamatórias em pacientes saudáveis submetidos às cirurgias eletivas de pequeno porte ${ }^{75,76}$. Dentre eles, cita-se pesquisa com pacientes submetidos à timpanoplastia sob anestesia com desflurano ou sevoflurano, onde a liberação de citocinas pró-inflamatórias foi maior com o emprego do primeiro anestésico $^{75}$. Ainda, relata-se também que a anestesia com sevoflurano não influenciou a concentração de citocinas inflamatórias em pacientes submetidos à cirurgia de extração de catarata ${ }^{76}$. Desta forma, não se conhece o comportamento exato destas citocinas em cirurgias menos agressivas em pacientes saudáveis.

Por conseguinte, torna-se necessário o aprofundamento em estudos da influência dos anestésicos propofol e isoflurano sobre a resposta inflamatória. E esta conduta torna-se essencial para intervenções futuras na prática médica, visando prevenção de resposta inflamatória adversa do paciente e melhora mais rápida de seu quadro no período peri-operatório. 


\section{Referências bibliográficas ${ }^{\mathrm{i}}$}

1. Kohl BA, Deutschman CS. The inflammatory response to surgery and trauma. Curr Opin Crit Care. 2006; 12: 325-32.

2. Hall GM, Ali W. The stress response and its modification by regional anaesthesia. Anaesthesia. 1998; 53: 10-2.

3. Arias JI, Aller MA, Arias J. Surgical Inflammation: a pathophysiological rainbow. J Transl Med. 2009; 7: 1-15.

4. Bochner BS. Systemic activation of basophils and eosinophils: markers and consequences. J Allergy Clin Immunol. 2000; 106: S292-302.

5. Idzko M, Sala AL, Ferrari D, Panther E, Herouy Y, Dichmann S, et al. Expression and function of histamine receptors in human monocyte-derived dendritic cells. $\mathrm{J}$ Allergy Clin Immunol. 2002; 109: 839-46.

6. Makrides SC. Therapeutic inhibition of the complement system. Pharmacol Rev. 1998; 50: 59-87.

7. Gerard C, Gerard NP. C5a anaphylatoxin and its seven transmembrane-segment receptor. Annu Rev Immunol. 1994; 12: 775-808.

8. Cicala C, Cirino G. Linkage between inflammation and coagulation: an update on molecular basis of the crosstalk. Life Sci. 1998; 62: 1817-24.

9. Esmon CT, Fukudome K, Mather T, Bode W, Regan LM, Stearns-Kurosawa DJ, et al. Inflammation, sepsis, and coagulation. Haematologica. 1999; 84: 254-9.

10. Plow EF, Herren T, Redlitz A, Miles LA, Hoover-Plow JL. The cell biology of the plasminogen system. Faseb J. 1995; 9: 939-45.

11. Loureiro-Silva MR, Molina HM, Borges DR. Substâncias vasoativas e a modulação do sistema microvascular hepático. Rev Assoc Med Bras. 1999; 45: 206-16.

12. Farmer SG, Burch RM. Biochemical and molecular pharmacology of kinin receptors. Annu Rev Pharmacol Toxicol. 1992; 32: 511-36.

13. Shimizu T. Lipid mediators in health and disease: enzymes and receptors as therapeutic targets for the regulation of immunity and inflammation. Annu Rev Pharmacol Toxicol. 2009; 49: 123-50.

14. Murakami M, Kudo I. Phospholipase A2. J Biochem. 2002; 131: 285-92.

15. Smith WL, Langenbach R. Why there are two cyclooxygenase isozymes. J Clin Invest. 2001; 107: 1491-5.

16. Thuresson ED, Lakkides KM, Rieke CJ, Sun Y, Wingerd BA, Micielli R, et al. Prostaglandin endoperoxide $\mathrm{H}$ synthase-1: the functions of cyclooxygenase active site residues in the binding, positioning, and oxygenation of arachidonic acid. $\mathbf{J}$ Biol Chem. 2001; 276: 10347-57.

17. Molina DM, Wetterholm A, Kohl A, McCarthy AA, Niegowski D, Ohlson E, et al. Structural basis for synthesis of inflammatory mediators by human leukotriene C4 synthase. Nature. 2007; 613-6.

18. Serhan CN, Chiang N, Van Dyke TE. Resolving inflammation: dual antiinflammatory and pro-resolution lipid mediators. Nat Rev Immunol. 2008; 8: 34961.

19. Cheng C-R. Inflammatory response to anesthesia and ways to attenuate it. Adv Anesth. 2005; 23: 107-41.

\footnotetext{
${ }^{\mathrm{i}}$ Referências bibliográficas apresentadas segundo as normas de Vancouver.
} 
20. Frankenstein Z, Alon U, Cohen IR. The immue-body cytokine network defines a social architecture of cell interactions. Biol Direct. 2006; 1: 1-15.

21. Oberholzer A, Oberholzer C, Moldawer LL. Sepsis syndromes: understanding the role of innate and acquired immunity. Shock. 2001; 16: 83-96.

22. Heinrich PC, Castell J, Andus T. Interleukin-6 and the acute phase response. Clin Sci. 1990; 265: 621-36.

23. Kurosawa S, Kato M. Anesthetics, immune cells, and immune responses. J Anesth. 2008; 22: 263-77.

24. Hawrylowicz CM, Howells GL, Feldmann M. Platelet-derived interleukin-1 induces human endothelial adhesion molecule expression and cytokine production. J Exp Med. 1991; 174: 785-90.

25. Kaplanski G, Farnarier C, Kaplanski S, Porat R, Shapiro L, Bongrand P, et al. Interleukin-1 induces interleukin- 8 secretion from endothelial cells by a juxtacrine mechanism. Blood. 1994; 84: 4242-8.

26. Bhagat K, Hingorani AD, Palacios M, Charles IG, Vallance P. Cytokine-induced venodilatation in humans in vivo: eNOS masquerading as iNOS. Cardiovasc Res. 1999; 41: 754-64.

27. Hehlgans T, Pfeffer K. The intriguing biology of the tumor necrosis factor/ tumor necrosis factor receptor superfamily: players, rules and the games. Immunology. 2005; 115: 1-20.

28. Ehlers S. Role of tumour necrosis factor (TNF) in host defence against tuberculosis: implications for immunotherapies targeting TNF. Ann Rheum Dis. 2003; 62: 37-42.

29. Nashleanas M, Kanaly S, Scott P. Control of Leishmania major infection in mice lacking TNF receptors. J Immunol. 1998; 160: 5506-13.

30. Castanos-Velez E, Maerlan S, Osorio LM, Aberg F, Biberfeld P, Orn A, et al. Trypanosoma cruzi infection in tumor necrosis factor receptor $\mathrm{p} 55$-deficient mice. Infect Immun. 1998; 66: 2960-8.

31. Kornman KS. Interleukin 1 genetics, inflammatory mechanisms, and nutrigenetic opportunities to modulate diseases of aging. Am J Clin Nutr. 2006; 83: 475S-83S.

32. Sodin-Semrl S, Taddeo B, Tseng D, Varga J, Fiore S. Lipoxin A4 inhibits IL-1 beta- induced IL-6, IL-8, and matrix metalloproteinase-3 production in human synovial fibroblasts and enhances synthesis of tissue inhibitors of metalloproteinases. J Immunol. 2000; 164: 2660-6.

33. Clauss M, Sunderkötter C, Sveinbjörnsson B, Hippenstiel S, Willuweit A, Marino $\mathrm{M}$, et al. A permissive role for tumor necrosis factor in vascular endothelial growth factor-induced vascular permeability. Blood. 2001; 97: 1321-9.

34. József L, Zouki C, Petasis NA, Serhan CN, Filep JG. Lipoxin A4 and aspirintriggered 15-epi-lipoxin A4 inhibit peroxynitrite formation, NF-kB and AP-1 activaton, and IL-8 gene expression in human leukocytes. Proc Natl Acad Sci. 2002; 99: 13266-71.

35. Kotani N, Hashimoto H, Sessler DI, Yasuda T, Ebina T, Muraoka M, et al. Expression of genes for proinflammatory cytokines in alveolar macrophages during propofol and isoflurane anesthesia. Anesth Analg. 1999; 89: 1250-6.

36. O'Garra A, Vieira P. TH1 cells control themselves by producing interleukin-10. Nat Rev Immunol. 2007; 7: 425-8.

37. de Waal Malefyt RAJ, Bennett B. Interleukin 10 (IL-10) inhibits cytokine synthesis by human monocytes: an autregulatory role of IL-10 produced by mopnocytes. J Exp Med. 1991; 174: 1209-20. 
38. Pestka S, Krause CD, Sarkar D, Walter MR, Shi Y, Fisher PB. Interleukin-10 and related cytokines and receptors. Annu Rev Immunol. 2004; 22: 929-79.

39. Moore KW, de Wall MR, Coffman RL, O'Garra A. Interleukin-10 and the interleukin-10 receptor. Annu Rev Immunol. 2001; 19: 683-765.

40. Woiciechowsky C, Asadullah K, Nestler D, Eberhardt B, Platzer C, Schöning B, et al. Sympathetic activation triggers systemic interleukin-10 release in immunodepression induced by brain injury. Nat Med. 1998; 4: 808-13.

41. Fiorentino DF, Bond MW, Mosmann TR. Two types of mouse T helper cell. IV. Th2 clones secrete a factor that inhibits cytokine production by Th1 clones. J Exp Med. 1989; 170: 2081-95.

42. Anderson CFOM, Kuchroo VJ, Sacks D. CD4+CD25-Foxp3- Th1 cells are the source of IL-10-mediated immune supression in chronic cutaneous leishmaniasis. J Exp Med. 2007; 204: 285-97.

43. Sozzani S, Ghezzi S, Iannolo G, Luini W, Borsatti A, Polentarutti N, et al. Interleukin 10 increases CCR5 expression and HIV infection in human monocytes. J Exp Med. 1998; 187: 439-44.

44. Takayama T, Morelli AE, Onai N, Hirao M, Matsushima K, Tahara H, et al. Mammalian and viral IL-10 enhance C-C chemokine receptor 7 expression by myeloid dendritic cells: impact on chemotactic responses and in vivo homing ability. J Immunol. 2001; 166: 136-43.

45. Dokka S, Shi X, Leonard S, Wang L, Castranova V, Rojanasakul Y. Interleukin10-mediated inhibition of free radical generation in macrophages. Am J Physiol Lung Cell Mol Physiol. 2001; 280: 1196-202.

46. Allavena P, Piemonti L, Longoni D, Bernasconi S, Stoppacciaro A, Ruco L, et al. IL-10 prevents the differentiation of monocytes to dendritic cells but promotes their maturation to macrophages. Eur J Immunol. 1998; 28: 359-69.

47. Fluckiger AC, Durand I, Banchereau J. Interleukin-10 induces apoptotic cell death of B-Chronic Lymphocytic Leukemia Cells. J Exp Med. 1994; 179: 91-9.

48. Masterson GR, Hunter JM. Does anaesthesia have long-term consequences? Br J Anaesth. 1996; 77: 569-71.

49. Meduri GU, Headley S, Kohler G, Stentz F, Tolley E, Umberger R, et al. Persistent elevation of inflammatory cytokines predicts a poor outcome in ARDS. Chest. 1995; 107: 1062-72.

50. El Azab SR, Rosseel PMJ, De Lange JJ, van Wijk EM, van Strik R, Scheffer GJ. Effect of VIMA with sevoflurane versus TIVA with propofol or midazolamsufentanil on the cytokine response during CABG surgery. Eur J Anaesthesiol. 2002; 19: 279-82.

51. Wilder RL. Hormones, pregnancy, and autoimmune diseases. Ann NY Acad Sci. 1998; 840: 45-50.

52. Gerard C, Bruyns C, Marchant A, Abramowicz D, Vandenabeele P, Delvaux A, et al. Interleukin 10 reduces the release of tumor necrosis factor and prevents lethality in experimental endotoxemia. J Exp Med. 1993; 177: 547-50.

53. Elenkov IJ, Chrousos GP. Stress hormones, proinflammatory and antiinflammatory cytokines, and autoimmunity. Ann N Y Acad Sci. 2002; 966: 290303.

54. Kehlet H. Surgical stress response: does endoscopic surgery confer an advantage? World J Surg. 1999; 23: 801-7.

55. Schietroma M, Carlei F, Mownah A, Franchi L, Mazzotta C, Sozio A, et al. Changes in the blood coagulation, fibrinolysis, and cytokine profile during laparoscopic and open cholecystectomy. Surg Endosc. 2004; 18: 1090-6. 
56. Matata BM, Sosnowski AW, Galinanes M. Off-pump bypass graft operation significantly reduces oxidative stress and inflammation. Ann Thorac Surg. 2000; 69: 785-91.

57. Wan S, Izzat MB, Lee TW, Wan IYP, Tang NLS, Yim APC. Avoiding cardiopulmonary bypass in multivessel CABG reduces cytokine response and myocardial injury. Ann Thorac Surg. 1999; 68: 52-7.

58. Oberholzer A, Souza SM, Tschoeke SK, Oberholzer C, Abouhamze A, Pribble JP, et al. Plasma cytokine measurements augment prognostic scores as indicators of outcome in patients with severe sepsis. Shock. 2005; 23: 488-93.

59. Zanotti S, Kumar A, Kumar A. Cytokine modulation in sepsis and septic shock. Expert Opin Invest Drugs. 2002; 11: 1061-75.

60. Rang HP, Dale MM, Ritter JM, Moore PK. Agentes anestésicos gerais. In: Farmacologia. 5a ed. Rio de Janeiro: Elsevier; 2004.

61. Little HJ. How has molecular pharmacology contributed to our understanding of the molecular mechanisms of general anaesthesia? Pharmacol Ther. 1996; 69: 3758.

62. Giraud O, Molliex S, Rolland C, Leçon-Malas V, Desmonts J-M, Aubier M, et al. Halogenated anesthetics reduce interleukin-1 beta-induced cytokine secretion by rat alveolar type II cells in primary culture. Anesthesiology. 2003; 92: 74-81.

63. Kotani N, Takahashi S, Sessler DI, Hashiba E, Kubota T, Hashimoto H, et al. Volatile anesthetics augment expression of proinflammatory cytokines in rat alveolar macrophages during mechanical ventilation. Anesthesiology. 1999; 91: 187-97.

64. Mitsuhata H, Shimizu R, Yokoyama MM. Supressive effects of volatile anesthetics on cytokine release in human peripheral blood mononuclear cells. Int $\mathbf{J}$ Immunopharmacol. 1995; 17: 529-34.

65. Rossano F, Tufano R, Cipollaro de L'ero G, Servillo G, Baroni A, Tufano MA. Anesthetic agents induce human mononuclear leucocytes to release cytokines. Immunopharmacol Immunotoxicol. 1992; 14: 439-50.

66. Crozier TA, Müller JE, Quittkat D, Sydow M, Wuttke W, Kettler D. Effect of anaesthesia on the cytokine response to abdominal surgery. Br J Anaesth. 1994; 72: $280-5$.

67. Ke JJ, Zhan J, Feng XB, Wu Y, Rao Y, Wang YL. A comparison of the effect of total intravenous anaesthesia with propofol and remifentanil and inhalational anaesthesia with isoflurane on the release of pro- and anti-inflammatory cytokines in patients undergoing open cholecystectomy. Anaesth Intensive Care. 2008; 36: 74-8.

68. Aarts L, van der Hee R, Dekker I, de Jong J, Langermeiger H, Bast A. The widely used anesthetic agent propofol can replace alfa-tocopherol as an antioxidant. FEBS Lett. 1995; 357: 83-5.

69. Galley HF, Dubbels AM, Webster NR. The effects of midazolam and propofol on interleukin-8 from human polymorphonuclear leukocytes. Anesth Analg. 1998; 86: $1289-93$.

70. Chen RM, Chen TG, Chen TL, Lin LL, Chang CC, Chang HC, et al. Antiinflammatory and antioxidative effects of propofol on lipopolyssaccharideactivated macrophages. Ann N Y Acad Sci. 2005; 1042: 262-71.

71. Cleary TG, Pickering LK. Mechanisms of intralipidic effect on polymorphonuclear leukocytes. J Clin Lab Immunol. 1983; 11: 21-6.

72. Salo M, Pirttikangas CO, Pulkki K. Effects of propofol emulsion and thiopentone on T helper cell type 1 /type 2 balance in vitro. Anesthesia. 1997; 52: 341-4. 
73. Loop T, Liu Z, Humar M, Hoetzel A, Benzing A, Pahl HL, et al. Thiopental inhibits the activation of nuclear factor kB. Anesthesiology. 2002; 96: 1202-13.

74. Larsen B, Hoff G, Wilhelm W, Buchinger H, Wanner G, Bauer M. Effect of intravenous anesthetics on spontaneous and endotoxin-stimulated cytokine response in cultured human whole blood. Anesthesiology. 1998; 89: 1218-27.

75. Koksal GM, Sayilgan C, Gungor G, Oz H, Sen O, Uzun H, et al. Effects of sevoflurane and desflurane on cytokine response during tympanoplasty surgery. Acta Anaesthesiol Scand. 2005; 49: 835-9.

76. Goto Y, Ho SL, McAdoo J, Fanning NF, Wang J, Redmond HP, et al. General versus regional anaesthesia for cataract surgery: effects on neutrophil apoptosis and the postoperative pro-inflammatory state. Eur J Anaesth. 2000; 17: 474-80. 
Capétula 02 Mamuscrita 
Perfil de citocinas inflamatórias em indivíduos submetidos a procedimentos cirúrgicos empregando propofol ou isoflurano ${ }^{\mathrm{ii}}$

Autores:

Marina Ázer Mazoti ${ }^{(1)}$, Mariana Gobbo Braz ${ }^{(1)}$, Norimar Hernandes Dias ${ }^{(2)}$, Leandro Gobbo Braz ${ }^{(3)}$, Márjorie de Assis Golim ${ }^{(4)}$, José Reinaldo Cerqueira Braz ${ }^{(3)}$, Daisy Maria Favero Salvadori ${ }^{(1)}$, Denise Fecchio ${ }^{(1)}$

(1) Departamento de Patologia, Faculdade de Medicina de Botucatu, Unesp - Univ Estadual Paulista, Brasil.

(2) Departamento de Oftalmologia, Otorrinolaringologia e Cirurgia de Cabeça e Pescoço, Faculdade de Medicina de Botucatu, Unesp - Univ Estadual Paulista, Brasil.

(3) Departamento de Anestesiologia, Faculdade de Medicina de Botucatu, Unesp Univ Estadual Paulista, Brasil.

(4) Hemocentro de Botucatu, Faculdade de Medicina de Botucatu, Unesp - Univ Estadual Paulista, Brasil.

Anestesia, cirurgia eletiva e citocinas inflamatórias

\footnotetext{
ii Trabalho apresentado segundo as normas da revista British Journal of Anaesthesia.
} 


\section{Resumo}

Introdução. Cirurgia gera no paciente uma resposta inflamatória conhecida como stress. Não está esclarecido o papel dos anestésicos voláteis e venosos na modulação do perfil de citocinas inflamatórias em pacientes saudáveis submetidos a cirurgias eletivas pouco invasivas. Assim, o objetivo deste trabalho foi estudar o perfil das citocinas IL-1 $\beta$, IL6 , IL-8, IL-10, IL-12 e TNF- $\alpha$ frente à anestesia inalatória com isoflurano e intravenosa com propofol, em pacientes saudáveis submetidos a cirurgias eletivas pouco invasivas.

Métodos. Quarenta pacientes ASA I, submetidos à cirurgia de otorrinolaringologia, foram alocados ao acaso para receber anestesia com isoflurano 1 CAM (concentração alveolar mínima) $(\mathrm{n}=20)$ ou com propofol 2 a $4 \mu \mathrm{g} \mathrm{mL} \mathrm{m}^{-1}(\mathrm{n}=20)$. Também foram administrados fentanil $5 \mathrm{mg} \mathrm{kg}$-1 e brometo de rocurônio $0,6 \mathrm{mg} \mathrm{kg}^{-1}$ a todos os pacientes. Foram coletados $10 \mathrm{~mL}$ de sangue venoso de cada paciente em cada um dos seguintes momentos: antes do início da cirurgia e anestesia (M1), 2 h após o início da cirurgia (M2) e no dia posterior ao ato anestésico-cirúrgico (M3). As concentrações plasmáticas das interleucinas IL-1 $\beta$, IL-6, IL-8, IL-10 e IL-12 e do fator de necrose tumoral TNF- $\alpha$ foram mensuradas em cada amostra pela técnica de citometria de fluxo, utilizando o método Cytometric Bead Array (CBA). Amostras de sangue venoso de quinze voluntários não submetidos a stress também foram coletadas como controle, dosando nessas amostras as mesmas citocinas.

Resultados. A comparação das concentrações plasmáticas de citocinas entre os grupos de anestésicos (M1) e o grupo de voluntários mostrou aumento de IL-8 nos grupos propofol e isoflurano. Os pacientes dos grupos isoflurano e propofol apresentaram baixas concentrações plasmáticas das citocinas pró-inflamatórias IL-1 $\beta$, IL-12 e TNF- $\alpha$ e da anti-inflamatória IL-10 no decorrer do período estudado. Já a concentração plasmática da IL-6 aumentou significativamente nos momentos M2 e M3 no grupo de pacientes que recebeu isoflurano, sendo que no grupo propofol o aumento ocorreu apenas em M3. Na comparação entre os dois grupos, a IL-6 apresentou maior concentração no grupo propofol em relação ao isoflurano em M3 (12,15 versus 6,85 pg $\left.\mathrm{mL}^{-1}, \mathrm{P}<0,05\right)$. Ainda, a IL-8 apresentou aumento na concentração plasmática apenas em M3 no grupo de pacientes que recebeu propofol.

Conclusões. Tomados em conjunto, os resultados indicam a liberação de IL-8 nos momentos anteriores à cirurgia e anestesia, caracterizados pelo medo ou ansiedade dos pacientes em serem submetidos a esses procedimentos. Em pacientes saudáveis submetidos às cirurgias pouco complexas, os resultados mostram liberação rápida e gradual de IL-6 frente à anestesia com isoflurano, enquanto com o emprego de propofol ocorre liberação tardia de IL-6 e IL-8. Os resultados permitem concluir que as diferentes técnicas e agentes anestésicos influenciam de maneira diferente o perfil de citocinas inflamatórias mesmo em pacientes saudáveis submetidos a cirurgias eletivas de pequeno porte.

\section{Palavras-chave}

anestésicos i.v., propofol; anestésicos voláteis, isoflurano; cirurgia eletiva; citocinas anti-inflamatórias; citocinas pró-inflamatórias; interleucina-6; interleucina-8; stress; técnicas de medições, citometria de fluxo. 


\begin{abstract}
Introduction. A surgery causes in the patient an inflammatory response known as stress. The role of volatile and venous anesthetics on the modulation of inflammatory cytokine profile in healthy patients subjected to minimally invasive elective surgeries is not elucidated. Thus, the aim of this paper was to study the profile of cytokines IL-1 $\beta$, IL- 6 , IL-8, IL-10, IL-12 and TNF- $\alpha$ under inhalation anesthesia with isoflurane and intravenous anesthesia with propofol in healthy patients subjected to minimally invasive elective surgeries.

Methods. Forty ASA-I patients, subjected to otorhinolaryngology surgery, were randomly allocated to receive anesthesia with isoflurane 1 MAC (minimum alveolar concentration) $(\mathrm{n}=20)$ or propofol 2 to $4 \mu \mathrm{g} \mathrm{mL}^{-1}(\mathrm{n}=20)$. Fentanyl $5 \mathrm{mg} \mathrm{kg}^{-1}$ and rocuronium bromide $0.6 \mathrm{mg} \mathrm{kg}^{-1}$ were also administered to all patients. Venous blood $(10 \mathrm{~mL})$ was collected from each patient at each of the following times: before the beginning of surgery and anesthesia (T1), $2 \mathrm{~h}$ after the beginning of surgery (T2), and on the day after the anesthetic-surgical procedure (T3). Plasma concentrations of interleukins IL-1 $\beta$, IL-6, IL-8, IL-10 and IL-12 and tumor necrosis factor (TNF- $\alpha$ ) were measured in each sample through flow cytometry technique by using the method Cytometric Bead Array (CBA). Venous blood samples from fifteen volunteers not subjected to stress were also collected as control, and the same cytokines were measured.

Results. Plasma concentrations of IL-8 increased in Propofol and Isoflurane groups (T1), compared to the group of volunteers. Patients of Isoflurane and Propofol groups had low plasma concentrations of proinflammatory cytokines IL-1 $\beta$, IL-12 and TNF- $\alpha$ and anti-inflammatory cytokine IL-10 throughout the study period. On the other hand, plasma concentration of IL-6 significantly increased at T2 and T3 in the group of patients who received isoflurane, whereas in Propofol group an increase only occurred at T3. Comparing groups, IL-6 concentration was higher in Propofol than in Isoflurane group at $\mathrm{T} 3\left(12.15\right.$ versus $\left.6.85 \mathrm{pg} \mathrm{mL}^{-1}, \mathrm{P}<0.05\right)$. In addition, the plasma concentration of IL-8 was higher only at T3 in the group of patients who received propofol.

Conclusions. Considered together, the results indicate IL-8 release at the times prior to surgery and anesthesia, which are characterized by the patients' fear and anxiety about being subjected to these procedures. For healthy patients subjected to minimally complex surgeries, results indicate a rapid and progressive IL-6 release under isoflurane anesthesia and a late IL-6 and IL-8 release under propofol anesthesia. The present results lead to the conclusion that the different anesthetic techniques and agents differently influence the inflammatory cytokine profile even in healthy patients subjected to minor elective surgeries.
\end{abstract}

\title{
Keywords
}

IV anesthetics; propofol; volatile anesthetics, isoflurane; elective surgery; antiinflammatory cytokines; proinflammatory cytokines; interleukin-6; interleukin-8; stress; mediation techniques; flow cytometry. 


\section{Introdução}

A lesão tecidual causada por trauma cirúrgico provoca no paciente uma resposta conhecida como stress ${ }^{1}{ }^{2}$. Esta resposta envolve um processo inflamatório responsável pelo reparo ao dano tecidual e promoção da homeostasia.

Para o desencadeamento, promoção e resolução de tal processo, é imprescindível a ação das citocinas inflamatórias que, por suas inúmeras funções, atuam como verdadeiro elo entre os diferentes sistemas fisiológicos ${ }^{2}$. As citocinas pró-inflamatórias induzem a síntese de proteínas de fase aguda pelo fígado, alteram a permeabilidade vascular, promovem o recrutamento de neutrófilos e macrófagos para o local da agressão, regulam a expressão e a síntese das proteínas envolvidas nas cascatas dos sistemas plasmáticos, promovem a liberação de hormônios relacionados ao stress, entre inúmeras outras funções ${ }^{3}$. Por outro lado, as anti-inflamatórias têm a função de inibir a liberação das pró-inflamatórias em monócitos e macrófagos e, assim, bloquear o processo inflamatório ${ }^{4}$. Como exemplos de citocinas envolvidas no stress em resposta ao trauma temos as pró-inflamatórias IL-1 $\beta$, IL-6, IL-8, IL-12 e TNF- $\alpha$ e a antiinflamatória IL-10 256 .

Apesar da liberação de citocinas inflamatórias ocorrer em resposta à lesão tecidual proveniente da incisão cirúrgica, o procedimento anestésico pode influenciá-la, o que pode alterar o curso do quadro peri-operatório ${ }^{7}$. Além da anestesia, outros fatores podem influenciar o stress, entre eles, a magnitude e a extensão do trauma tecidual e as variações biológicas individuais ${ }^{3}$.

O propofol é um agente anestésico intravenoso utilizado tanto para indução quanto para manutenção anestésica ${ }^{8}$. Produz poucos efeitos colaterais e apresenta propriedades não-anestésicas como: atividade anti-emética ${ }^{9}$, propriedade analgésica ${ }^{10}$, possível efeito ansiolítico ${ }^{11}$, efeito anti-oxidante ${ }^{12}$ e amnésia ${ }^{13}$, entre outras. Já o 
isoflurano é um anestésico volátil e, como o propofol, também possui atividades nãoanestésicas. Dentre elas, destaca-se o papel protetor sobre o miocárdio, já que diminui a demanda cardíaca por oxigênio ${ }^{14}$.

A técnica anestésica, se inalatória ou intravenosa, e o anestésico empregado também podem modular de forma diferente a resposta ao trauma, principalmente o perfil de citocinas ${ }^{3}$. Trabalhos recentes com anestésicos voláteis, como o isoflurano, e com anestésicos intravenosos, como o propofol, têm mostrado aumento na liberação de citocinas pró-inflamatórias, tais como IL-6, IL-8 e TNF- $\alpha$ em cirurgias abdominais, cardíacas e torácicas ${ }^{15-17}$, além de liberação de IL-10, citocina anti-inflamatória, em cirurgias abdominais ${ }^{15}$.

É importante notar a predominância de trabalhos na literatura analisando o perfil de citocinas inflamatórias em pacientes já comprometidos por alguma doença ${ }^{15-17}$. Entretanto, a resposta inflamatória em pacientes saudáveis submetidos a procedimentos cirúrgicos de pequena complexidade é pouco estudada ${ }^{18}{ }^{19}$. Dentre os poucos relatos, cita-se pesquisa com cirurgia de timpanoplastia, onde a liberação de citocinas inflamatórias foi maior em pacientes anestesiados com desflurano, em comparação com sevoflurano ${ }^{18}$. Também há relato de cirurgia de catarata, onde o anestésico sevoflurano não influenciou a concentração de citocinas inflamatórias nos pacientes estudados ${ }^{19}$.

Sendo assim, o objetivo deste trabalho foi estudar o perfil das citocinas IL-1 $\beta$, IL-6, IL-8, IL-10, IL-12 e TNF- $\alpha$ frente à anestesia inalatória com isoflurano e intravenosa com propofol, em pacientes saudáveis submetidos a cirurgias eletivas pouco invasivas. 


\section{Métodos}

O protocolo do estudo foi aprovado pelo Comitê de Ética em Pesquisa da Faculdade de Medicina de Botucatu [143/08-CEP] e o Termo de Consentimento Livre e Esclarecido foi obtido de todos os pacientes após preenchimento de questionário (Anexos 1 e 2).

O trabalho foi realizado com quarenta pacientes adultos, com idade entre 18 e 50 anos, de ambos os sexos e classificados pela Sociedade Americana de Anestesiologia (ASA) como ASA-I (indivíduos saudáveis, que não apresentam outra doença a não ser a patologia cirúrgica). As cirurgias realizadas foram septoplastia, adenoamigdalectomia, timpanoplastia e sinusotomia. O uso regular de álcool e medicamentos e o recebimento de radiação dentro de um período de trinta dias foram considerados critérios de exclusão.

Buscando analisar a influência do stress psicológico advindo da submissão à cirurgia e anestesia nestes pacientes, foram coletadas amostras de sangue venoso (10 mL) de quinze voluntários saudáveis não submetidos à cirurgia ou qualquer outra forma de stress (pesquisa em andamento). Estas amostras foram utilizadas como controle ao serem comparadas com as amostras dos pacientes.

A consulta pré-anestésica dos pacientes foi realizada para obter seu histórico completo e realizar seu exame clínico.

Todos os pacientes receberam medicação pré-anestésica na sala de operação com midazolam $3 \mathrm{mg}$ por via intravenosa (iv). Os pacientes foram distribuídos aleatoriamente em dois grupos, de acordo com o tipo de anestésico utilizado. Para casualização dos grupos, foram previamente preparados 40 envelopes contendo o número de cada um dos pacientes do estudo, bem como a indicação do grupo, pela colocação do nome do anestésico intravenoso (propofol) ou inalatório (isoflurano). Os 
envelopes foram fechados e misturados. Cada um deles foi fixado ao protocolo de estudo, sendo aberto imediatamente antes da realização da anestesia, garantindo, dessa forma, a casualidade dos grupos. Cada grupo foi formado por vinte pacientes. Monitorou-se a pressão arterial de forma não invasiva, a frequência cardíaca, a saturação periférica de oxi-hemoglobina e o bloqueio neuromuscular (aparelho TOF Guard; Organon Tekinika, Bélgica). O isoflurano (quando foi o caso) e o oxigênio inspirado e expirado também foram monitorados, além da pressão expiratória final de dióxido de carbono $\left(\mathrm{PetCO}_{2}\right)$ (aparelho de anestesia Primus da Dräeger Medical; Lübeck, Alemanha). A fração inspirada de oxigênio $\left(\mathrm{FiO}_{2}\right)$ foi mantida a 0,5 e a $\mathrm{PetCO}_{2}$ de 30 a 35 mmHg por meio de alterações na frequência respiratória. Foram registradas, para todos os pacientes, a duração da anestesia e cirurgia, as concentrações expiradas de isoflurano, a concentração plasmática predita de propofol e o consumo total de propofol em pacientes pertencentes ao grupo Propofol.

A indução da anestesia, no grupo isoflurano, foi realizada com propofol $2 \mathrm{mg} \mathrm{kg}^{-}$ ${ }^{1}$ e, no grupo propofol, com infusão alvocontrolada desse anestésico por bomba de infusão computadorizada (Diprifusor, Fresenius Vial, Brezins, França). Em ambos os grupos, utilizou-se fentanil $5 \mathrm{mg} \mathrm{kg}^{-1}$ e brometo de rocurônio $0,6 \mathrm{mg} \mathrm{kg}^{-1}$ iv. No grupo propofol, a concentração plasmática predita de propofol foi de 2 a $4 \mu \mathrm{g} \mathrm{mL} \mathrm{m}^{-1}$ até o final da cirurgia, enquanto que no grupo isoflurano, o anestésico inalatório foi mantido em uma concentração alveolar mínima (CAM - 1,2\%). Os pulmões foram ventilados mecanicamente com volume controlado, utilizando-se volume corrente de $8 \mathrm{~mL} \mathrm{~kg}^{-1} \mathrm{e}$ fluxo de gases de $40 \%$ de oxigênio em ar comprimido. A adequação da anestesia foi avaliada com base nas respostas hemodinâmicas. Em ambos os grupos, doses adicionais de fentanil $2 \mu \mathrm{g} \mathrm{kg}^{-1}$ e rocurônio $0,2 \mathrm{mg} \mathrm{kg}^{-1}$ foram utilizadas quando necessárias. Caso necessário, o bloqueio neuromuscular foi revertido com neostigmina $3 \mu \mathrm{g} \mathrm{kg}^{-1} \mathrm{e}$ 
atropina $10 \mu \mathrm{g} \mathrm{kg}^{-1}$ iv, no final da cirurgia. A extubação traqueal foi realizada após a reversão completa do bloqueio neuromuscular. Todos os pacientes receberam medicação analgésica (dipirona $1 \mathrm{~g}$ e tramadol $100 \mathrm{mg}$ ) e antiemética (ondansetrona 8 mg) após o final da cirurgia. Os pacientes, após a cirurgia, foram encaminhados para a sala de recuperação pós-anestésica. Nenhum paciente apresentou complicação cirúrgica e tiveram alta hospitalar de acordo com normas estabelecidas para cada procedimento cirúrgico.

Amostras de sangue venoso foram coletadas dos pacientes antes do início da cirurgia e anestesia, ou seja, imediatamente antes da medicação pré-anestésica e da indução da anestesia, considerado o momento controle (M1), 2 h após o início da cirurgia (M2) e no dia posterior ao ato anestésico-cirúrgico (M3). Foram coletados, em tubo com heparina sódica, $10 \mathrm{~mL}$ de sangue venoso, por paciente, em cada um dos momentos.

As amostras de sangue foram centrifugadas a $1500 \mathrm{rpm}$ por $10 \mathrm{~min}$ imediatamente após a coleta e o plasma obtido foi aliquotado e armazenado à - $80^{\circ} \mathrm{C}$ para posterior análise.

Todas as amostras foram analisadas pelo mesmo pesquisador. As concentrações plasmáticas de IL-1 $\beta$, IL-6, IL-8, IL-10, IL-12 e TNF- $\alpha$ foram determinadas pela técnica de citometria de fluxo. Para isso, utilizou-se o kit $\mathrm{BD}^{\mathrm{TM}}$ Cytometric Bead Array (CBA) Human Inflammation (Becton Dickinson, San Diego, CA, EUA), onde foram seguidas as instruções do fabricante. A sensibilidade das citocinas IL-1 $\beta$, IL-6, IL-8, IL-10, IL12 e TNF- $\alpha$ foram 7,2 , 2,5 , 3,6, 3,3 , 1,9 e 3,7 $\mathrm{pg} \mathrm{mL}^{-1}$, respectivamente.

$\mathrm{O}$ kit $\mathrm{BD}^{\mathrm{TM}} \mathrm{CBA}$ Human Inflammation permite a quantificação de citocinas inflamatórias utilizando seis diferentes populações de partículas. Estas partículas são marcadas com intensidades discretamente diferentes de PerCP (peridinin clorophil 
protein), cuja fluorescência pode ser lida pelo canal FL3 em citômetro de fluxo. Cada população de partículas com determinada intensidade de fluorescência representa um analito (citocina) e é revestida com anticorpos de captura específicos para uma dada citocina. Devido à diferença na intensidade de fluorescência das partículas, todas puderam ser misturadas em um único tubo e, assim, as seis citocinas inflamatórias foram analisadas simultaneamente em uma mesma amostra de plasma (50 $\mu \mathrm{L})$. As citocinas presentes nas amostras analisadas ligaram-se às partículas marcadas com PerCP para formação do complexo citocina-partícula. A detecção dos analitos foi realizada pela ligação destes complexos com os correspondentes anticorpos específicos conjugados com PE (phycoerythrin). Esta marcação proporciona sinais de fluorescência nas partículas apropriadas, os quais foram lidos em canal FL2.

Em cada experimento também foi utilizada uma curva-padrão para cada citocina, a qual foi preparada a partir de uma amostra padrão contendo citocina humana liofilizada na concentração de $5000 \mathrm{pg} \mathrm{mL}^{-1}$. A partir dessa concentração, foi realizada diluição seriada até a concentração de $20 \mathrm{pg} \mathrm{mL}^{-1}$. O controle negativo para a curvapadrão $\left(0 \mathrm{pg} \mathrm{mL}^{-1}\right)$ também foi utilizado.

Os dados foram adquiridos em citômetro de fluxo BD FACSCalibur ${ }^{\mathrm{TM}}$ (Becton Dickinson, San Jose, CA, EUA) utilizando o software BD CellQuest ${ }^{\mathrm{TM}}$ (Becton $^{\text {B }}$ Dickinson, San Diego, CA, EUA). Antes desta etapa, foi realizada a calibração do aparelho com o software BD FACSComp ${ }^{\mathrm{TM}}$ (Becton Dickinson, San Diego, CA, EUA).

Para aquisição dos dados, foram contados 1800 eventos para cada amostra, os quais foram plotados em gráficos FL3 versus FL2, indicando as populações de partículas e as intensidades de fluorescência de cada citocina. A análise dos dados em pg $\mathrm{mL}^{-1}$ foi realizada no software BD $\mathrm{CBA}^{\mathrm{TM}}$ (Becton Dickinson, San Diego, CA, EUA). 
A análise estatística foi realizada pela técnica de análise de variância nãoparamétrica para o modelo de medidas repetidas em grupos independentes, complementada com os testes de comparações entre os postos médios dos grupos nos diferentes momentos de avaliação ${ }^{20}$. Ainda, foram realizados testes de correlação entre a duração da cirurgia e a liberação de citocinas em cada grupo de anestésico. Para duração da cirurgia e liberação de IL-6 foi realizado teste de Correlação de Spearman, enquanto que a comparação entre duração da cirurgia e liberação de IL-8 foi realizada pelo teste de Correlação de Pearson. Todas as comparações foram realizadas no valor de $5 \%$ de significância. 


\section{Resultados}

A proposta deste trabalho foi avaliar o efeito de isoflurano e propofol sobre o perfil de citocinas inflamatórias em pacientes saudáveis submetidos a cirurgias eletivas.

As cirurgias de otorrinolaringologia realizadas foram septoplastia, adenoamigdalectomia, timpanoplastia e sinusotomia. Analisando as características dos pacientes e o tipo de cirurgia (Tabela 1), não foi observada diferença entre os grupos de pacientes anestesiados com isoflurano ou propofol. Ainda, não foi observada diferença significativa, entre os dois grupos de pacientes, quanto à administração de fentanil e brometo de rocurônio (Tabela 1). Entretanto, as cirurgias do grupo propofol foram significativamente mais longas que as do grupo isoflurano (Tabela 1). Para observar se esta diferença na duração da cirurgia poderia influenciar de forma significativa a liberação de citocinas, foram realizados testes de correlação entre o período da cirurgia e a concentração plasmática de IL-6 e IL-8, não sendo observada correlação positiva para nenhuma delas $(\mathrm{P}>0,05)$.

A concentração alveolar mínima (CAM) de isoflurano foi mantida a 1,20\%, apresentando-se ligeiramente mais baixa aos 30 min de cirurgia e ao seu final (Tabela 2). A pressão arterial sistólica destes pacientes foi significativamente maior antes da indução anestésica, sendo que a pressão expiratória total de $\mathrm{CO}_{2}$ apresentou-se mais elevada ao final da cirurgia (Tabela 2). Os valores referentes à frequência cardíaca, pressão arterial diastólica e pressão expiratória de $\mathrm{O}_{2}$ não diferiram durante a cirurgia sob anestesia com isoflurano (Tabela 2).

Já a dose predita de propofol foi de 2 a $4 \mu \mathrm{g} \mathrm{kg}^{-1}$ para manutenção da anestesia neste grupo de pacientes. A administração das maiores doses ocorreu aos 90 e 120 minutos de cirurgia (Tabela 3). A pressão arterial sistólica destes pacientes foi significativamente menor aos 30 minutos de cirurgia (Tabela 3). Os valores referentes à 
frequência cardíaca, pressão arterial diastólica e pressão expiratória de $\mathrm{O}_{2}$ e pressão expiratória total de $\mathrm{CO}_{2}$ não diferiram durante a cirurgia sob anestesia com propofol (Tabela 3).

Não foi observada diferença significativa nas concentrações plasmáticas das citocinas IL-1 $\beta$, IL-6, IL-8, IL-10, IL-12 e TNF- $\alpha$ entre os pacientes dos grupos isoflurano ou propofol, no momento anterior ao início da cirurgia e anestesia (M1). Buscando analisar a influência do stress psicológico advindo da submissão à cirurgia e anestesia nestes pacientes, estas concentrações, (M1), foram comparadas com as do grupo de voluntários. Nesta comparação, pacientes prestes a se submeter ao procedimento anestésico-cirúrgico (com propofol ou isoflurano) apresentaram valores de IL-8 significativamente maiores que os voluntários acima referidos (Tabela 4).

Quanto à concentração plasmática das citocinas pró-imflamatórias IL-1 $\beta$, IL-12 e TNF- $\alpha$ e da anti-inflamatória IL-10, não foi observada diferença significativa nos momentos M2 e M3 em relação ao M1, tanto com propofol quanto com isoflurano, nem entre os anestésicos utilizados (Tabela 5).

Entretanto, outras citocinas pró-inflamatórias apresentaram diferença em suas concentrações plasmáticas ao longo do período estudado. A concentração plasmática de IL-6, em pacientes anestesiados com isoflurano, aumentou significativamente nos momentos M2 e M3 em relação ao M1 (Figura 1), enquanto que pacientes anestesiados com propofol apresentaram aumento significativo dessa citocina somente no dia posterior ao ato anestésico-cirúrgico (M3). Comparando os valores desta citocina entre pacientes sob as diferentes anestesias, dentro de um mesmo período de tempo, observou-se que a concentração plasmática de IL-6 foi maior em pacientes que receberam propofol no dia posterior ao ato anestésico-cirúrgico (M3) (Figura 1). 
Ainda, a concentração plasmática de IL-8 aumentou significativamente no momento M3 nos pacientes sob anestesia venosa. Entretanto, o aumento dessa citocina não foi observado em pacientes anestesiados com isoflurano. Comparando as concentrações plasmáticas entre os dois grupos, não foi observada diferença significativa (Figura 2). 


\section{Discussão}

O presente estudo demonstrou que o emprego dos anestésicos isoflurano e propofol influencia o perfil de citocinas inflamatórias em pacientes saudáveis submetidos a cirurgias eletivas de pequeno porte. A anestesia com isoflurano resulta em aumento na liberação de IL-6, enquanto que a anestesia com propofol resulta em aumento de IL-6 e IL-8. Os resultados também demonstraram que propofol influencia uma liberação maior e mais tardia de IL-6 no período peri-operatório em relação ao isoflurano.

A quantificação das citocinas inflamatórias foi realizada pela técnica de Citometria de Fluxo, por meio de Cytometric Bead Array (CBA) para citocinas inflamatórias humanas. Em relação ao tradicional ELISA (enzyme-linked immunsorbent assay), a metodologia empregada é vantajosa pela sua praticidade, já que a dosagem simultânea das seis citocinas reduz o volume necessário de amostra. Além disso, a alta sensibilidade do CBA é comparável à do ELISA $^{21}$.

Alguns resultados, quando analisados em conjunto, podem sugerir que qualquer diferença no perfil das citocinas inflamatórias poderia ser atribuída em grande parte ao anestésico per se. Entre eles, o fato de os pacientes anestesiados com propofol ou isoflurano não diferirem quanto ao sexo, idade, raça, peso ou altura e quanto ao tipo de cirurgia. Além disso, o fato de não ser observada correlação positiva entre duração da cirurgia e liberação de IL-8 ou IL-6 poderia sugerir que a duração da cirurgia não teria influência sobre a maior liberação destas. Também é importante ressaltar que foi feita a escolha de pacientes apresentando bom estado de saúde, sendo estes submetidos a cirurgias de pequena complexidade, para que houvesse a menor interferência possível dos fatores doença e cirurgia sobre o perfil das citocinas inflamatórias. 
Outro ponto a ser ressaltado na análise do perfil de citocinas frente à anestesia é a administração de diferentes fármacos aos pacientes. No início do procedimento anestésico-cirúrgico, todos os pacientes receberam fentanil. Este analgésico opióide apresenta efeito inibitório sobre as respostas celular e humoral, inclusive sobre a expressão de citocinas ${ }^{22}$. Prednisona, potente anti-inflamatório glicocorticóide, também foi administrado aos pacientes. Uma dos mecanismos anti-inflamatórios dos glicocorticóides ocorre pela supressão da transcrição de citocinas pelo fator de transcrição nuclear kappa B (NF-kB) quando este é reprimido por receptores intracitoplasmáticos de glicocorticóides ${ }^{23}$.

Pelos mecanismos de ação destes fármacos, poder-se-ia sugerir que fentanil e prednisona teriam inibido a liberação das citocinas inflamatórias, visto que as concentrações plasmáticas de IL-1 $\beta$, IL-10, IL-12 e TNF- $\alpha$ apresentaram-se baixas ao longo do período estudado, tanto em pacientes anestesiados com isoflurano, quanto com propofol. Quanto às IL-6 e IL-8, poder-se-ia sugerir que a sua liberação seria ainda maior que a observada, se o fentanil ou prednisona não tivessem sido administrados. Entretanto, essas sugestões são excluídas pelos importantes fatos de que não houve diferença quanto à administração de fentanil entre os dois grupos estudados e de que o comportamento das citocinas inflamatórias mostrou-se semelhante com ou sem a administração de prednisona.

A maior liberação de IL-8, no momento antes do inicio da cirurgia e anestesia, observada entre os pacientes anestesiados com isoflurano ou propofol, com relação aos indivíduos não submetidos a stress cirúrgico, podem sugerir que o stress psicológico já aumenta a liberação desta citocina. Esta liberação imediata de IL-8, portanto, pode ter ocorrido frente à ansiedade ou medo de ser submetido a um procedimento anestésicocirúrgico. A liberação de citocinas pró-inflamatórias após a submissão de diversas 
formas de stress psicológico, de fato, é relatada na literatura ${ }^{24}$. Entretanto, até o momento pesquisado, não foram encontrados relatos analisando o stress psicológico em decorrência da submissão à cirurgia.

O fato de os pacientes incluídos no presente estudo apresentarem estado físico ASA-I indica que são indivíduos saudáveis, sem qualquer condição clínica que os prédisponham às complicações pós-operatórias. Os baixos valores plasmáticos de IL-1 $\beta$, IL-10, IL-12 e TNF- $\alpha$ no período peri-operatório, com o emprego de isoflurano ou propofol, confirmam o estado de saúde dos mesmos, condizente com o estado ASA-I. De fato, concentrações plasmáticas elevadas e persistentes de IL-1 $\beta$ e TNF- $\alpha$ estão relacionadas com a patogenia de várias complicações clínicas pós-cirúrgicas, tais como choque séptico ${ }^{25}$ e síndrome do stress respiratório em adultos (ARDS) ${ }^{26}$. Ainda, concentrações plasmáticas elevadas de IL-12, se acompanhada de elevação de outras, tais como IL-1 $\beta$, IL-6, IL-8, IL-10 e TNF- $\alpha$, podem caracterizar um quadro de sepse ${ }^{27}$.

Com relação às cirurgias pouco complexas, os baixos valores de IL-1 $\beta$, IL-10, IL-12 e TNF- $\alpha$, ao longo do período peri-operatório, confirmam trabalho de Goto e cols ${ }^{19}$, os quais não observaram diferença significativa quanto à liberação de IL-1 $\beta$ e TNF- $\alpha$ em pacientes submetidos à cirurgia de extração de catarata com o emprego de sevoflurano. Entretanto, os resultados do presente estudo diferem daqueles apresentados por Koksal e cols ${ }^{18}$, que observaram aumento nas concentrações de IL-1 $\beta$ e TNF- $\alpha$ em pacientes submetidos à timpanoplastia sob anestesia com desflurano ou sevoflurano.

O estudo da influência da anestesia sobre o perfil de citocinas inflamatórias em cirurgias eletivas pouco invasivas foi escolhido pelo fato de que há poucos relatos na literatura com foco neste tipo de cirurgia. Observa-se predominância de estudos com média ou grande complexidade cirúrgica e, ainda assim, os resultados mostram-se, por vezes, contraditórios. Como exemplos, há relatos de aumento ${ }^{28}$ e diminuição ${ }^{29}$ da 
citocina anti-inflamatória IL-10 após cirurgias cardíacas com o emprego de isoflurano. Neste mesmo tipo de cirurgia, há relatos de aumento ${ }^{16}$ e manutenção ${ }^{29}$ dos valores plasmáticos de IL-8 tanto em pacientes anestesiados com anestésicos voláteis quanto com propofol. Ainda, TNF- $\alpha$ encontra-se aumentado ${ }^{28}$ e diminuído ${ }^{16}$ quando empregado anestésico volátil em cirurgias cardíacas.

O isoflurano é um composto halogenado empregado na anestesia geral inalatória. O aumento na concentração plasmática de IL-6 após cirurgia de pequeno porte, sob anestesia inalatória com composto halogenado, observado por este trabalho, é respaldado por Koksal e colaboradores ${ }^{18}$, os quais relatam esse aumento em cirurgias também de timpanoplastia sob anestesia com desflurano ou sevoflurano. Ainda, os mesmos autores verificaram a liberação de IL-6 após indução anestésica (e antes do início da cirurgia), mostrando que os anestésicos voláteis possuem efeito sobre a liberação de citocinas pró-inflamatórias mesmo em pacientes submetidos às cirurgias eletivas.

A resposta inflamatória em resposta ao procedimento anestésico-cirúrgico é proporcional à agressão cirúrgica ${ }^{2}$. De fato, a liberação de IL-6 ao longo do período pós-operatório sob anestesia com isoflurano, encontrada neste estudo, foi menor que a encontrada em cirurgias como colecistectomia, histerectomia e cirurgias cardíacas sob o mesmo agente anestésico $\begin{array}{llll}15 & 16 & 29 & 30\end{array}$. Nestas cirurgias, os pacientes foram classificados como ASA-II e III, o que indica a presença de co-morbidades associadas, o que já pode indicar concentrações elevadas de citocinas. Ainda, o dano tecidual oriundo do trauma cirúrgico nessas cirurgias foi maior que o apresentado pelo presente estudo. Dessa forma, pode-se indicar, por estes resultados, menor resposta inflamatória ao trauma em cirurgias menos invasivas, já que a IL-6 pode ser considerada parâmetro para a extensão da lesão tecidual. 
Com relação aos anestésicos venosos, um dos mais empregados atualmente é o propofol. A liberação de IL-6 com o emprego de propofol, observada por este estudo, confirma estudos anteriores, realizados em cirurgias abdominais ${ }^{15}$ e cardíacas ${ }^{16}$, nas quais os pacientes foram submetidos ao mesmo anestésico. Já a liberação de IL-8 também foi observada em cirurgias cardíacas ${ }^{16}$. Entretanto, é importante notar que esses trabalhos referem-se à cirurgia de grande porte. Entretanto, a liberação de IL-6 e IL-8, em pacientes saudáveis sob cirurgias pouco invasivas, ocorrida de forma tardia, pode sugerir retardo na liberação sob influência deste anestésico. Esta liberação mais tardia é relatada por Crozier e colaboradores ${ }^{31}$, os quais estudaram o efeito do propofol em cirurgia de histerectomia.

Uma possível explicação para o retardo na liberação de citocinas inflamatórias com o emprego do propofol pode estar relacionada com a propriedade antioxidante deste anestésico. O propofol apresenta estrutura química que lembra a molécula do $\alpha$ tocoferol (vitamina E), conhecida vitamina antioxidante ${ }^{8}$. O efeito anti-oxidante do propofol pode estar relacionado com sua inibição sobre o fator de transcrição nuclear kappa B (NF-kB), o qual, por sua vez, influencia a síntese de citocinas inflamatórias. De fato, Sanchez-Conde e colaboradores ${ }^{32}$ demonstraram que a anestesia com propofol diminuiu a expressão de NF-kB por células renais de pacientes submetidos à cirurgia vascular.

A liberação de IL-6 e de IL-8, observada durante procedimento anestésicocirúrgico, tem importante papel no processo inflamatório. Nesta resposta, a IL-6, entre inúmeras atividades, estimula a síntese de proteínas de fase aguda pelo fígado e induz a expressão de fatores teciduais e a ativação de neutrófilos, enquanto que a quimiotaxia destas células é realizada pela IL-8 ${ }^{5}$. Estas atividades são importantes para a cicatrização e reparo do tecido agredido pela incisão cirúrgica. 
A atividade e a expressão de IL-8 têm sido fortemente associadas à presença de IL-6 em casos de stress em resposta ao procedimento anestésico-cirúrgico, o que pode explicar a concomitante presença destas citocinas em pacientes anestesiados com propofol.

O TNF- $\alpha$ e a IL-1 $\beta$ são duas das principais citocinas que inicializam o processo inflamatório, agindo de forma conjunta. Entre suas funções, promovem a liberação de citocinas como a IL-6. Em contrapartida, a IL-6 pode atenuar a atividade de TNF- $\alpha$ e IL-1 $\beta$ ao promover a liberação de receptores para estas últimas ${ }^{33}$. De fato, os pacientes anestesiados, de ambos os grupos, apresentaram baixas concentrações plasmáticas de TNF- $\alpha$ e IL-1 $\beta$ ao longo do período estudado, enquanto que a concentração plasmática de IL-6 apresentou-se aumentada, o que poderia sugerir a ação de IL-6 sobre a concentração das outras duas citocinas.

Ainda, o aumento de IL-1 $\beta$ e TNF- $\alpha$ durante a cirurgia pode ser inicial e transitório $^{2}$, já que apresentam meia vida curta. O TNF- $\alpha$ apresenta meia vida in vivo menor que vinte minutos ${ }^{5}$, resultado de rápida degradação desta citocina no plasma. Estes fatos poderiam sugerir que a liberação destas citocinas pode ter ocorrido logo após o trauma tecidual, não sendo detectado por este estudo pelos momentos da coleta (M2 e M3) serem superiores à sua meia-vida.

O trauma tecidual oriundo da cirurgia promove, portanto, a liberação de citocinas pró-inflamatórias, modulando o stress em resposta ao trauma. A associação entre citocinas e trauma tecidual parece ter relação com o eixo hipotalâmico-pituitárioadrenal (HPA). De fato, IL-6 e IL-8 apresentam papel imprescindível no stress em resposta ao procedimento anestésico-cirúrgico ao estimular este eixo que, juntamente com o sistema nervoso autonômico, liberam neurotransmissores e hormônios ${ }^{34}$. Dentre os neurotransmissores liberados citam-se norepinefrina e epinefrina, e dentre os 
hormônios, cortisol e hormônio adrenocorticotrófico. Este último, por sua vez, inibe a liberação de IL-6. Desta forma, poderia ser sugerido que a liberação de IL-6, pelos pacientes dos grupos isoflurano e propofol, poderia estimular o eixo HPA.

Já os anestésicos gerais influenciam o stress em resposta à cirurgia ao afetar diretamente o sistema imune ou ao estimular o eixo HPA e o sistema nervoso simpático 34. Em ambs os casos, os anestésicos podem influenciar o perfil de citocinas inflamatórias. Ao afetar o sistema imunológico, os anestésicos podem atuar diretamente sobre as células envolvidas no processo inflamtório ou influenciar a expressão e secreção de mediadores inflamatórios.

Entretanto, é importante ressaltar que os mecanismos celulares pelos quais os anestésicos atuam ainda não estão esclarecidos. Alguns trabalhos relatam a influência da anestesia geral inalatória sobre células alveolares com diminuição de citocinas inflamatórias após o estímulo da cultura celular com anestésico halogenado ${ }^{35}$, indicando efeito inibidor sobre a resposta inflamatória. Entretanto, outros autores verificaram efeito estimulador da expressão e liberação de citocinas pró-inflamatórias após estímulo de cultura celular com agentes anestésicos inalatórios ou intravenosos ${ }^{37}$ 38. Ainda, a não interferência do anestésico venoso sobre a liberação das citocinas inflamatórias IL-6 e IL-8 em cultura de células também foi observado ${ }^{39}$.

Os resultados encontrados indicam que a escolha do anestésico pode influenciar de maneira diferente a liberação de citocinas mesmo em pacientes saudáveis. A IL-8 só apresentou aumento em sua concentração em pacientes anestesiados com propofol. Enquanto isso, a concentração plasmática de IL-6 aumentou de forma mais rápida com isoflurano, e mais tardia com propofol. No entanto, estes resultados diferem de outros trabalhos, que relatam liberação maior de IL-6 com o emprego de anestésico volátil, se comparado à anestesia com propofol, quando realizadas histerectomia ${ }^{31}$ ou cirurgia 
cardíaca ${ }^{16}$. Dessa forma, com relação à influência sobre o stress, o anestésico propofol parece promover um atraso na liberação de citocinas inflamatórias e, em comparação com isoflurano, promover liberação maior em momento posterior. Os resultados, então, mostram que, mesmo pacientes sem manifestações clínicas de doença, quando submetidos a procedimentos eletivos de pequeno porte, apresentam diferentes perfis de citocinas quando submetidos a diferentes técnicas anestésicas.

É importante ressaltar que a interpretação dos valores plasmáticos de citocinas inflamatórias em pacientes submetidos a procedimentos cirúrgicos torna-se difícil pela impossibilidade de, na prática, dissociar os danos causados pela cirurgia do emprego da anestesia. Além disso, há variação quanto ao tipo de citocina estudada e seus momentos de avaliação, dificultando ainda mais a análise e a padronização.

Embora as citocinas inflamatórias sejam mediadores imprescindíveis para a resposta ao procedimento anestésico-cirúrgico e elo entre os sistemas fisiológicos, o stress não pode ser avaliado por completo apenas sob a ótica das citocinas. Estudos posteriores poderiam mensurar outros mediadores também envolvidos nesta resposta inflamatória e correlacioná-los com as citocinas.

Tomados em conjunto, os resultados indicam a liberação de IL-8 nos momentos anteriores à cirurgia e anestesia, caracterizados pelo medo ou ansiedade dos pacientes em ser submetido a esses procedimentos. Ainda, os resultados mostram liberação rápida e gradual de IL-6 frente à anestesia com isoflurano, em pacientes saudáveis submetidos às cirurgias pouco complexas. Com o emprego de propofol, ocorre liberação tardia de IL-6 e IL-8, mesmo em pacientes saudáveis submetidos às cirurgias pouco complexas. Os resultados também demonstram que as diferentes técnicas anestésicas e os diferentes anestésicos influenciam de maneira diferente o perfil de citocinas inflamatórias mesmo em pacientes saudáveis submetidos a cirurgias eletivas de pequeno porte. 


\section{Financiamento}

Este trabalho foi financiado pela Fundação de Amparo à Pesquisa do Estado de São Paulo (FAPESP) e pelo Conselho Nacional de Desenvolvimento Científico e Tecnológico (CNPq). 


\section{Agradecimentos}

Nós agradecemos ao Dr. Rodrigo Pestana, assessor científico da empresa Becton Dickinson, pelo valioso auxílio na análise dos dados. Nós gostaríamos de agradecer ao Dr. Carlos Roberto Padovani, Professor Titular do departamento de Bioestatística do Instituto de Biociências da UNESP, pelo excelente auxílio na análise estatística. 


\section{Referências}

1 Kohl BA, Deutschman CS. The inflammatory response to surgery and trauma. Curr Opin Crit Care 2006; 12: 325-32

2 Hall GM, Ali W. The stress response and its modification by regional anaesthesia. Anaesthesia 1998; 53: 10-2

3 Cheng C-R. Inflammatory response to anesthesia and ways to attenuate it. $A d v$ Anesth 2005; 23: 107-41

4 Moore KW, de Wall MR, Coffman RL, O'Garra A. Interleukin-10 and the interleukin-10 receptor. Annu Rev Immunol 2001; 19: 683-765

5 Jawa RS, Kulaylat MN, Baumann H, Dayton MT. What is new in cytokine research related to trauma/critical care. J Intensive Care Med 2006; 21: 63-85

6 Sheeran P, Hall GM. Cytokines in anaesthesia. Br J Anaesth 1997; 78: 201-19

7 Schneemilch CE, Schilling T, Bank U. Effects of general anaesthesia on inflammation. Baillieres Best Pract Res Clin Anaesthesiol 2004; 18: 493-507

8 Vasileiou I, Xanthos T, Koudouna E, et al. Propofol: a review of its non-anesthetic effects. Eur J Pharmacol 2009; 605: 1-8

9 Borgeat A, Stirnemann HR. Antiemetic effect of propofol. Anaesthesist 1998; 47: 918-24

10 Dong XP, Xu TL. The actions of propofol on gamma-aminobutyric acid-A and glycine receptors in acutely dissociated spinal dorsal horn neurons of the rat. Anaesth Analg 2002; 95: 907-14

11 Matsuo M, Ayuse T, Oi K, Kataoka Y. Propofol produces anticonflict action by inhibiting 5-HT release in rat dorsal hipocampus. Neuroreport 1997; 8: 3087-90

12 Ansley DM, Lee J, Godin DV, Garnett ME, Qayumi AK. Propofol enhances red cell antioxidant capacity in swine and humans. Can J Anaesth 1998; 88: $362-70$

13 Nordstrom O, Sandin R. Recall during intermittent propofol anaesthesia. $\mathrm{Br} J$ Anaesth 1996; 76: 699-701

14 Landoni G, Bignami E, Oliviero F, Zangrillo A. Halogenated anaesthetics and cardiac protection in cardiac and non-cardiac anaesthesia. Ann Cardiac Anaesth 2009; 12: 4-9

15 Ke JJ, Zhan J, Feng XB, Wu Y, Rao Y, Wang YL. A comparison of the effect of total intravenous anaesthesia with propofol and remifentanil and inhalational anaesthesia with isoflurane on the release of pro- and anti-inflammatory cytokines in patients undergoing open cholecystectomy. Anaesth Intensive Care 2008; 36: 748

16 El Azab SR, Rosseel PMJ, De Lange JJ, van Wijk EM, van Strik R, Scheffer GJ. Effect of VIMA with sevoflurane versus TIVA with propofol or midazolamsufentanil on the cytokine response during CABG surgery. Eur J Anaesthesiol 2002; 19: 279-82

17 De Conno E, Steurer MP, Wittlinger M, et al. Anesthetic-induced improvement of the inflammatory response to one-lung ventilation. Anesthesiology 2009; 110: 1316-26

18 Koksal GM, Sayilgan C, Gungor G, et al. Effects of sevoflurane and desflurane on cytokine response during tympanoplasty surgery. Acta Anaesthesiol Scand 2005; 49: $835-9$

19 Goto Y, Ho SL, McAdoo J, et al. General versus regional anaesthesia for cataract surgery: effects on neutrophil apoptosis and the postoperative pro-inflammatory state. Eur J Anaesth 2000; 17: 474-80

20 Zar JH. Biostatistical analysis. New Jersey: Prentice-Hall, 1999 
21 Chen R, Lowe L, Wilson J, et al. Simultaneous measurement of six cytokines in a single sample using microparticle-based flow cytometric technology. Clin Chem 1999; 9: 1693-4

$22 \mathrm{Wu}$ Y, Wang Y, Zhan J. Effects of remifentanyl and fentanyl on LPS-induced cytokine release in human whole blood in vitro. Mol Biol Rep 2009; 36: 1113-7

23 Goulding NJ. The molecular complexity of glucocorticoid actions in inflammation - a four-ring circus. Curr Opin Pharmacol 2004; 4: 629-36

24 Steptoe A, Hamer M, Chida Y. The effects of acute psychological stress on circulating inflammatory factors in humans: a review and meta-analysis. Brain Behav Immun 2007

25 Meduri GU, Headley S, Kohler G, et al. Persistent elevation of inflammatory cytokines predicts a poor outcome in ARDS. Chest 1995; 107: 1062-72

26 Oberholzer A, Oberholzer C, Moldawer LL. Sepsis syndromes: understanding the role of innate and acquired immunity. Shock 2001; 16: 83-96

27 Oberholzer A, Souza SM, Tschoeke SK, et al. Plasma cytokine measurements augment prognostic scores as indicators of outcome in patients with severe sepsis. Shock 2005; 23: 488-93

28 Gilliland HE, Armstrong MA, Carabine U, McMurray TJ. The choice of anesthetic maintenance technique influences the antiinflammatory cytokine response to abdominal surgery. Anesth Analg 1997; 85: 1394-8

29 Corcoran TB, Engel A, Sakamoto H, O'Shea A, O'Callaghan-Enright S, Shorten GD. The effects of propofol on neutrophil function, lipid peroxidation and inflammatory response during elective coronary artery bypass grafting in patients with impaired ventricular function. Br J Anaesth 2006; 97: 825-31

30 Roth-Isigkeit A, Borstel TV, Seyfarth M, Schmucker P. Perioperative serum levels of tumor-necrosis-factor alpha (TNF- $\alpha$ ), IL-1 $\beta$, IL-6, IL-10 and soluble IL-2 receptor in patients undergoing cardiac surgery with cardiopulmonary bypass without and with correction for haemodilution. Clin Exp Immunol 1999; 118: 242-6

31 Crozier TA, Müller JE, Quittkat D, Sydow M, Wuttke W, Kettler D. Effect of anaesthesia on the cytokine response to abdominal surgery. Br J Anaesth 1994; 72 : 280-5

32 Sanchez-Conde P, Rodriguez-Lopez JM, Nicolas JL, et al. The comparative abilities of propofol and sevoflurane to modulate inflammation and oxidative stress in the kidney after aortic cross-clamping. Anesth Analg 2008; 106: 371-8

33 Lin E, Calvano SE, Lowry SF. Inflammatory cytokines and cell response in surgery. Surgery 2000; 127: 117-26

34 Kurosawa S, Kato M. Anesthetics, immune cells, and immune responses. J Anesth 2008; 22: 263-77

35 Boost KA, Flondor M, Hofstetter C, et al. The beta-adrenoreceptor antagonist propanolol counteracts anti-inflammatory effects of isoflurane in rat endotoxemia. Acta Anaesthesiol Scand 2007; 51: 900-8

36 Giraud O, Molliex S, Rolland C, et al. Halogenated anesthetics reduce interleukin-1 beta-induced cytokine secretion by rat alveolar type II cells in primary culture. Anesthesiology 2003; 92: 74-81

37 Kotani N, Hashimoto H, Sessler DI, et al. Expression of genes for proinflammatory cytokines in alveolar macrophages during propofol and isoflurane anesthesia. Anesth Analg 1999; 89: 1250-6

38 Rossano F, Tufano R, Cipollaro de L'ero G, Servillo G, Baroni A, Tufano MA. Anesthetic agents induce human mononuclear leucocytes to release cytokines. Immunopharmacol Immunotoxicol 1992; 14: 439-50 
39 Larsen B, Hoff G, Wilhelm W, Buchinger H, Wanner G, Bauer M. Effect of intravenous anesthetics on spontaneous and endotoxin-stimulated cytokine response in cultured human whole blood. Anesthesiology 1998; 89: 1218-27 


\section{Tabelas e figuras}

Tabela 1 Características dos pacientes, tipos e duração das cirurgias e administração de medicamentos nos grupos anestesiados com isoflurano ou propofol.

\begin{tabular}{lll}
\hline Variáveis & $\begin{array}{l}\text { Grupo Isoflurano } \\
\mathbf{n = 2 0}\end{array}$ & $\begin{array}{l}\text { Grupo Propofol } \\
\mathbf{n}=\mathbf{2 0}\end{array}$ \\
\hline Sexo $(\mathrm{M} / \mathrm{F})$ & $12 / 8^{(1)}$ & $10 / 10$ \\
Idade (anos) & $25(18-45)^{(2)}$ & $23(18-50)$ \\
Raça (branca/parda) & $19 / 1$ & $18 / 2$ \\
Peso $(\mathrm{kg})$ & $66,5(42,0-88,0)$ & $61,0(48,0-80,0)$ \\
Altura $(\mathrm{cm})$ & $170(154-182)$ & $165(153-181)$ \\
Septoplastia & 15 & 13 \\
Timpanoplastia & 2 & 5 \\
Adenoamigdalectomia & 3 & 1 \\
Sinusotomia & 0 & 1 \\
Duração cirurgia (min) & $132,5(90,0-225,0)$ & $157,5(110,0-225,0)$ \\
Fentanil $\left(\mu \mathrm{g} \mathrm{kg}^{-1}\right)$ & $412,5(250,0-800,0)$ & $475,0(350,0-750,0)$ \\
Brometo de rocurônio $\left(\mu \mathrm{g} \mathrm{kg}{ }^{-1}\right)$ & $42,0(30,0-62,0)$ & $48,0(30,0-70,0)$ \\
\hline (1) Valores expressos em número absoluto; & \\
(2) Valores expressos em mediana (valor mínimo e máximo). & \\
\hline
\end{tabular}

Tabela 2 Cinética dos atributos anestésicos no grupo de pacientes anestesiado com isoflurano.

\begin{tabular}{|c|c|c|c|c|c|c|c|}
\hline \multirow[b]{2}{*}{ Variável } & \multicolumn{6}{|c|}{ Momento (min) } & \multirow[b]{2}{*}{$\begin{array}{l}\text { Valor } \\
\text { de p }\end{array}$} \\
\hline & $\begin{array}{c}\text { Antes } \\
\text { da } \\
\text { indução }\end{array}$ & 30 & 60 & 90 & 120 & Final & \\
\hline $\mathrm{CAM}^{(1)}$ & - & $\begin{array}{c}0,90 \mathrm{~b}^{(2)} \\
{[0,80 ; 1,00]}\end{array}$ & $\begin{array}{c}1,10 \mathrm{ab} \\
{[0,85 ; 1,20]}\end{array}$ & $\begin{array}{c}1,20 \mathrm{a} \\
{[1,00 ; 1,25]}\end{array}$ & $\begin{array}{c}1,20 \mathrm{a} \\
{[1,05 ; 1,02]}\end{array}$ & $\begin{array}{c}0,85 \mathrm{~b} \\
{[0,60 ; 1,20]}\end{array}$ & $<0,001$ \\
\hline $\mathrm{FC}$ & $\begin{array}{c}80,0 \\
{[70,5 ; 96,0]}\end{array}$ & $\begin{array}{c}79,0 \\
{[71,5 ; 93,0]}\end{array}$ & $\begin{array}{c}80,0 \\
{[72,5 ; 88,5]}\end{array}$ & $\begin{array}{c}77,5 \\
{[73,0 ; 92,0]}\end{array}$ & $\begin{array}{c}83,0 \\
{[74,0 ; 96,5]}\end{array}$ & $\begin{array}{c}79,0 \\
{[68,5 ; 91,5]}\end{array}$ & 0,16 \\
\hline PAS & $\begin{array}{c}132,0 \mathrm{a} \\
{[120,5 ; 138,5]}\end{array}$ & $\begin{array}{c}102,0 \mathrm{~b} \\
{[92,0 ; 113,5]}\end{array}$ & $\begin{array}{c}108,0 \mathrm{~b} \\
{[100,5 ; 119,5]}\end{array}$ & $\begin{array}{c}108,0 \mathrm{~b} \\
{[103,5 ; 117,5]}\end{array}$ & $\begin{array}{c}112,0 \mathrm{ab} \\
{[101,5 ; 129,0]}\end{array}$ & $\begin{array}{c}113,0 \mathrm{ab} \\
{[101,5 ; 127,5]}\end{array}$ & $<0,001$ \\
\hline PAD & $\begin{array}{c}73,5 \mathrm{a} \\
{[65,5 ; 78,0]}\end{array}$ & $\begin{array}{c}54,0 \mathrm{~b} \\
{[47,5 ; 62,5]}\end{array}$ & $\begin{array}{c}61,0 \mathrm{ab} \\
{[50,5 ; 70,5]}\end{array}$ & $\begin{array}{c}61,5 \mathrm{ab} \\
{[54,0 ; 68,0]}\end{array}$ & $\begin{array}{c}62,0 \mathrm{ab} \\
{[55,5 ; 71,0]}\end{array}$ & $\begin{array}{c}64,5 \mathrm{ab} \\
{[55,0 ; 71,5]}\end{array}$ & 0,002 \\
\hline $\mathrm{SpO}_{2}$ & $\begin{array}{c}97,0 \\
{[96,0 ; 97,0]}\end{array}$ & $\begin{array}{c}97,0 \\
{[97,0 ; 98,0]}\end{array}$ & $\begin{array}{c}98,0 \\
{[96,5 ; 98,0]}\end{array}$ & $\begin{array}{c}97,5 \\
{[97,0 ; 98,0]}\end{array}$ & $\begin{array}{c}97,5 \\
{[97,0 ; 98,0]}\end{array}$ & $\begin{array}{c}98,0 \\
{[97,0 ; 98,0]}\end{array}$ & 0,08 \\
\hline $\mathrm{PetCO}_{2}$ & ב & $\begin{array}{c}33,0 \mathrm{ab} \\
{[32,0 ; 34,0]}\end{array}$ & $\begin{array}{c}33,0 \mathrm{~b} \\
{[32,0 ; 34,0]}\end{array}$ & $\begin{array}{c}33,0 \mathrm{ab} \\
{[31,7 ; 34,0]}\end{array}$ & $\begin{array}{c}34,0 \mathrm{ab} \\
{[33,0 ; 36,0]}\end{array}$ & $\begin{array}{c}35,0 \mathrm{a} \\
{[33,0 ; 37,0]}\end{array}$ & 0,001 \\
\hline
\end{tabular}
pressão arterial sistólica (mm $\mathrm{Hg}$ ); PAD: pressão arterial diastólica (mm $\mathrm{Hg}$ ); $\mathrm{SpO}_{2}$ : pressão expiratória de $\mathrm{O}_{2}(\mathrm{~mm} \mathrm{Hg})$; PetCO ${ }_{2}$ : pressão expiratória final de $\mathrm{CO}_{2}(\mathrm{~mm} \mathrm{Hg})$.

(2) Momentos seguidos de mesma letra não diferem estatisticamente. Os valores são dados em mediana e os $1^{\underline{0}}$ e $3^{0}$ quartis apresentam-se entre colchetes. Valores são referentes aos momentos e variáveis. 
Tabela 3 Cinética dos atributos anestésicos no grupo anestesiado com propofol.

\begin{tabular}{|c|c|c|c|c|c|c|c|}
\hline \multirow[b]{2}{*}{ Variável } & \multicolumn{6}{|c|}{ Momento (min) } & \multirow[b]{2}{*}{$\begin{array}{c}\text { Valor } \\
\text { de } p\end{array}$} \\
\hline & $\begin{array}{c}\text { Antes } \\
\text { da } \\
\text { indução }\end{array}$ & 30 & 60 & 90 & 120 & Final & \\
\hline $\mathrm{DP}^{(1)}$ & - & $\begin{array}{c}3,2 b^{(2)} \\
{[3,0 ; 3,5]}\end{array}$ & $\begin{array}{c}3,6 \mathrm{ab} \\
{[3,0 ; 4,0]}\end{array}$ & $\begin{array}{c}3,8 \mathrm{a} \\
{[3,4 ; 4,2]}\end{array}$ & $\begin{array}{c}3,9 \mathrm{a} \\
{[3,4 ; 5,0]}\end{array}$ & $\begin{array}{c}3,7 \mathrm{ab} \\
{[2,4 ; 5,0]}\end{array}$ & $<0,01$ \\
\hline $\mathrm{FC}$ & $\begin{array}{c}77,0 \\
{[71,0 ; 90,5]}\end{array}$ & $\begin{array}{c}76,5 \\
{[68,0 ; 83,5]}\end{array}$ & $\begin{array}{c}76,0 \\
{[64,0 ; 86,5]}\end{array}$ & $\begin{array}{c}80,5 \\
{[64,0 ; 88,5]}\end{array}$ & $\begin{array}{c}76,0 \\
{[68,0 ; 83,5]}\end{array}$ & $\begin{array}{c}77,5 \\
{[62,0 ; 83,5]}\end{array}$ & 0,89 \\
\hline PAS & $\begin{array}{c}116,0 \mathrm{a} \\
{[110,0 ; 129]}\end{array}$ & $\begin{array}{c}101,0 \mathrm{~b} \\
{[93,0 ; 112,0]}\end{array}$ & $\begin{array}{c}107,0 \mathrm{ab} \\
{[99,0 ; 121]}\end{array}$ & $\begin{array}{c}110,0 \mathrm{a} \\
{[108,0 ; 123,0]}\end{array}$ & $\begin{array}{c}114,0 \mathrm{a} \\
{[105,0 ; 126,0]}\end{array}$ & $\begin{array}{c}120,0 \mathrm{a} \\
{[111,0 ; 127,0]}\end{array}$ & $<0,01$ \\
\hline PAD & $\begin{array}{c}70,0 \mathrm{a} \\
{[65,0 ; 74,0]}\end{array}$ & $\begin{array}{c}58,0 \mathrm{~b} \\
{[46,0 ; 67,0]}\end{array}$ & $\begin{array}{c}64,0 \mathrm{ab} \\
{[57,0 ; 73,0]}\end{array}$ & $\begin{array}{c}65,0 \mathrm{ab} \\
{[55,0 ; 70,0]}\end{array}$ & $\begin{array}{c}69,0 \mathrm{ab} \\
{[62,0 ; 83,0]}\end{array}$ & $\begin{array}{c}71,0 \mathrm{a} \\
{[65,0 ; 79,0]}\end{array}$ & 0,003 \\
\hline $\mathrm{SpO}_{2}$ & $\begin{array}{c}97,0 \\
{[96,0 ; 98,0]}\end{array}$ & $\begin{array}{c}97,0 \\
{[97,0 ; 98,0]}\end{array}$ & $\begin{array}{c}98,0 \\
{[97,0 ; 98,0]}\end{array}$ & $\begin{array}{c}98,0 \\
{[97,0 ; 98,0]}\end{array}$ & $\begin{array}{c}97,0 \\
{[97,0 ; 98,0]}\end{array}$ & $\begin{array}{c}97,0 \\
{[97,0 ; 98,0]}\end{array}$ & 0,06 \\
\hline $\mathrm{PetCO}_{2}$ & {$[-2,0, \infty, 0]$} & $\begin{array}{c}33,5 \mathrm{ab} \\
{[32,0 ; 35,0]}\end{array}$ & $\begin{array}{c}32,0 \mathrm{~b} \\
{[31,0 ; 33,5]}\end{array}$ & $\begin{array}{c}34,0 \mathrm{ab} \\
{[31,5 ; 34,5]}\end{array}$ & $\begin{array}{c}33,0 \mathrm{ab} \\
{[32,0 ; 34,5]}\end{array}$ & $\begin{array}{c}34,0 \mathrm{a} \\
{[33,0 ; 35,5]}\end{array}$ & 0,024 \\
\hline
\end{tabular}

(1) DP: dose predita de propofol $\left(\mu \mathrm{g} \mathrm{Kg}^{-1}\right)$; FC: frequência cardíaca (bpm); PAS: pressão arterial sistólica (mm Hg); PAD: pressão arterial diastólica $(\mathrm{mm} \mathrm{Hg}) ; \mathrm{SpO}_{2}$ : pressão expiratória de $\mathrm{O}_{2}$ $(\mathrm{mm} \mathrm{Hg}) ; \mathrm{PetCO}_{2}$ : pressão expiratória final de $\mathrm{CO}_{2}(\mathrm{~mm} \mathrm{Hg})$.

(2) Momentos seguidos de mesma letra não diferem estatisticamente. Os valores são dados em mediana e os $1^{\underline{0}}$ e $3^{\underline{0}}$ quartis apresentam-se entre colchetes. Valores são referentes aos momentos e variáveis.

Tabela 4 Concentrações plasmáticas $\left(\mathrm{pg} \mathrm{mL}^{-1}\right)$ de citocinas inflamatórias nos grupos anestesiados com isoflurano e propofol (M1) e no grupo de voluntários ${ }^{\mathbf{1}}$.

\begin{tabular}{|c|c|c|c|c|}
\hline \multirow[b]{2}{*}{ Citocina } & \multicolumn{3}{|c|}{ Grupo } & \multirow[b]{2}{*}{ Valor p } \\
\hline & Isoflurano & Propofol & Voluntários & \\
\hline IL- $1 \beta$ & $2,45(0,00-4,30)$ & $1,40(0,00-4,80)$ & $1,30(0,00-3,70)$ & $\mathrm{P}>0,05$ \\
\hline IL-6 & $2,25(0,00-4,60)$ & $2,10(0,00-5,40)$ & $2,10(0,00-3,00)$ & $\mathrm{P}>0,05$ \\
\hline IL-8 & $7,10(0,00-13,90) b$ & $5,65(0,00-8,70) \mathrm{b}^{(2)}$ & $1,50(0,00-3,10) \mathrm{a}$ & $\mathrm{P}<0,01$ \\
\hline IL-10 & $1,80(0,00-4,60)$ & $1,85(0,00-4,80)$ & $1,40(0,00-2,40)$ & $\mathrm{P}>0,05$ \\
\hline TNF- $\alpha$ & $1,40(0,00-6,20)$ & $0,00(0,00-7,00)$ & $0,00(0,00-3,80)$ & $\mathrm{P}>0,05$ \\
\hline \multicolumn{5}{|c|}{$\begin{array}{l}\text { (1) M1: antes do início da cirurgia e anestesia. Os dados são apresentados em mediana (valor mínimo - } \\
\text { máximo). Teste não paramétrico de Kruskal - Wallis. } \\
\text { (2) Duas medianas seguidas de uma mesma letra minúscula não diferem }(\mathrm{P}<0,01) \text { quanto aos }\end{array}$} \\
\hline
\end{tabular}




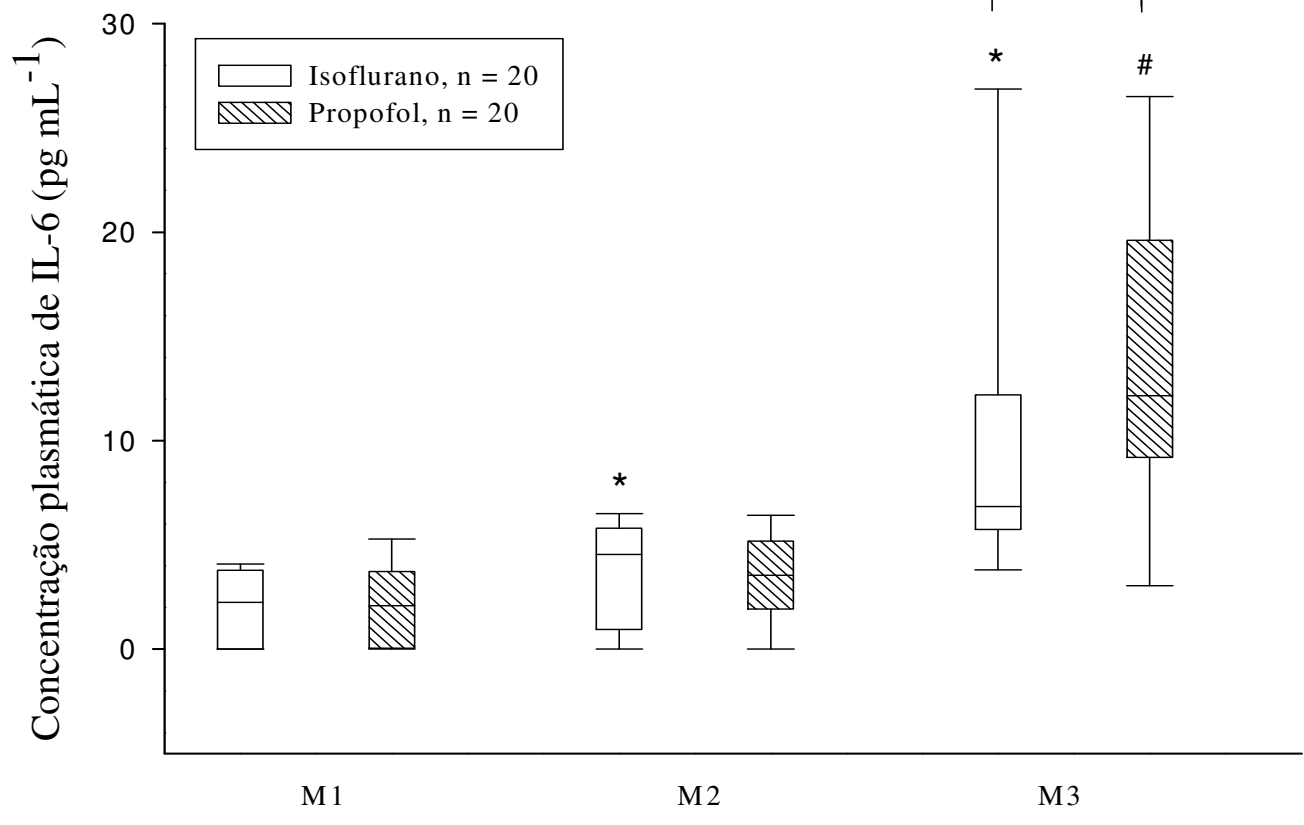

Fig 1: Concentração plasmática de IL-6: antes do início da cirurgia e anestesia (M1); 2 h após início da cirurgia (M2) e no dia posterior ao ato anestésico-cirúrgico (M3). Em cada box, os quadrantes inferior e superior representam, respectivamente, 25 e $75 \%$ dos valores, o traço horizontal, a mediana e, as barras de erro, os percentis 5 e 95 . $\mathrm{P}<0,05$.

*: diferença significativa dentro do grupo isoflurano,

\#: diferença dentro do grupo propofol; \&: diferença entre os grupos. 


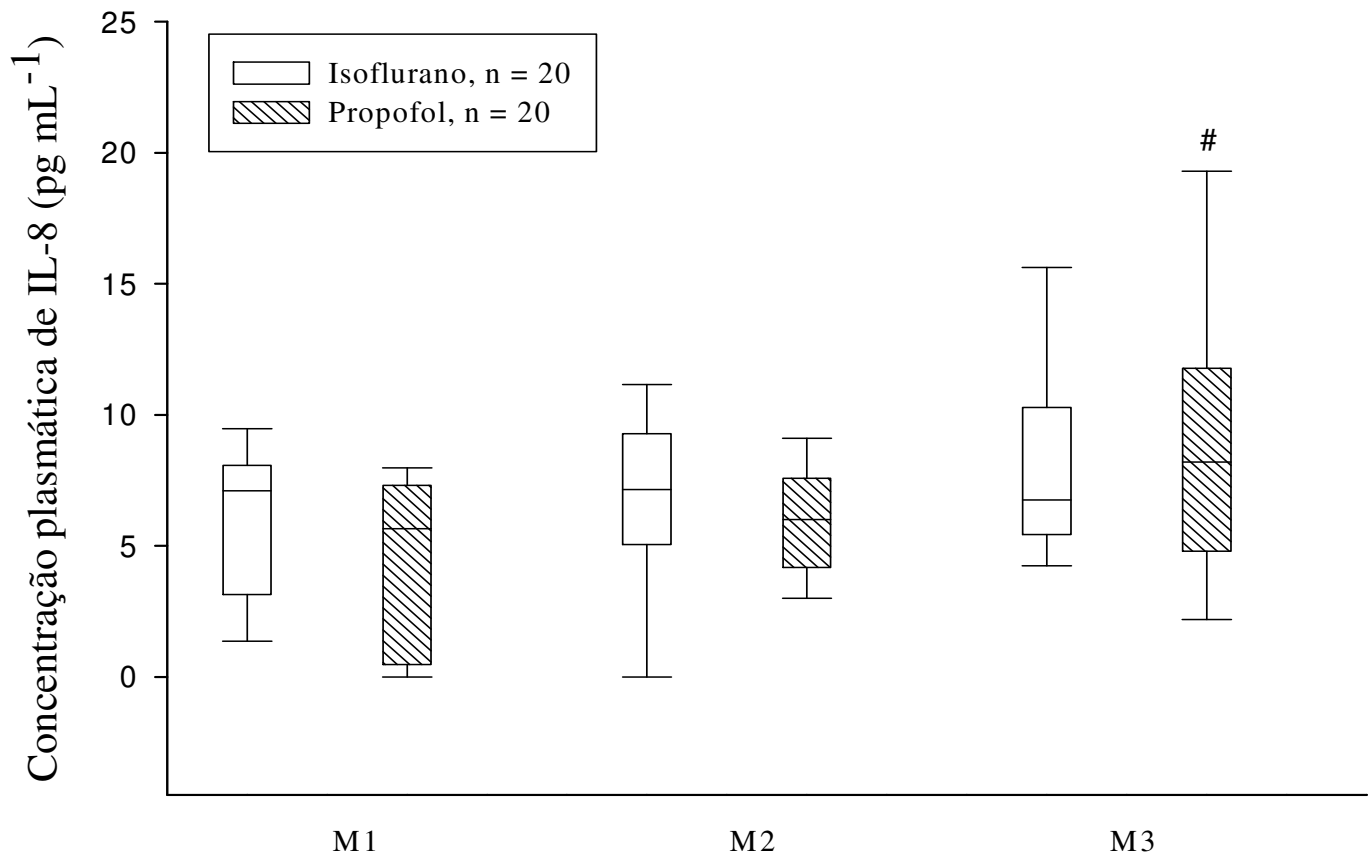

Fig 2 Concentração plasmática de IL-8: antes do início da cirurgia e anestesia (M1), 2h após o início da cirurgia (M2) e no dia posterior ao ato anestésico-cirúrgico (M3). Em cada box, os quadrantes inferior e superior representam, respectivamente, 25 e $75 \%$ dos valores, o traço horizontal, a mediana e, as barras de erro, os percentis 5 e 95.

\# indica diferença significativa dentro do grupo propofol $\mathrm{P}<0,05$; 
Anexas 


\section{Anexo 1}

TERMO DE CONSENTIMENTO LIVRE E ESCLARECIDO

I. Identificação do paciente (RG hospitalar: )

\begin{tabular}{|l|l|l|}
\hline \multicolumn{2}{|l|}{ Nome: } \\
\hline Endereço: \\
\hline Cidade: & Estado: & Bairro: \\
\hline CEP: & Telefone: \\
\hline
\end{tabular}

\section{Título da Pesquisa}

Perfil de citocinas inflamatórias em indivíduos submetidos a procedimentos cirúrgicos empregando propofol ou isoflurano

Pesquisador-Responsável: Marina Ázer Mazoti, Aluna de Pós-Graduação do Departamento de Patologia - Faculdade de Medicina, UNESP, Botucatu - SP. Endereço Residencial: R. Primo Paganini, 471. Jardim Panorama. Botucatu/SP. Telefone (14) 3813-2513; e-mail: marina_mazoti@yahoo.com.br.

Professora-Orientadora: Dra. Denise Fecchio, Pesquisadora do Departamento de Patologia - Faculdade de Medicina, UNESP, Botucatu - SP. Endereço Residencial: Avenida Universitária, 3168. Altos do Paraíso. Botucatu/SP. Telefone (14) 38146866; e-mail: dfecchio@fmb.unesp.br.

\section{Explicações do pesquisador ao paciente}

O objetivo desta pesquisa é analisar a resposta inflamatória do indivíduo que recebe anestesia inalatória ou aplicada na veia (endovenosa) ao passar por uma cirurgia. Para essa análise, iremos quantificar algumas proteínas presentes na circulação sangüínea, chamadas citocinas. O benefício para você não será direto e não comprometerá a cirurgia a que será submetido. Para melhor interpretação dos resultados, iremos comparar aqueles obtidos das anestesias inalatória (isoflurano) e venosa (propofol). Serão utilizados anestésicos normalmente utilizados em anestesias 
gerais (inalatória e venosa) no Hospital das Clínicas. Os pacientes serão escolhidos por sorteio após escolha feita pelos médicos dos anestésicos, os quais não interferem no procedimento cirúrgico. Não haverá, portanto, qualquer interferência da presente pesquisa para a escolha do anestésico a ser empregado e o paciente sorteado será alocado no respectivo grupo experimental somente após a escolha do anestésico.

Desta forma, solicitamos seu consentimento para que sejam coletadas amostras de $10 \mathrm{ml}$ de sangue periférico antes da cirurgia, durante a anestesia e no $1^{\mathrm{o}}$ dia após a cirurgia (pós-operatório). A coleta será realizada por profissional experiente e é procedimento com pequeno desconforto e risco mínimo, já que será utilizado material estéril e descartável. Será realizado, também, um questionário sobre seu estilo de vida e história médica; todas as informações são de caráter confidencial e sua identidade será preservada. O paciente, aceitando participar da pesquisa, também assinará um termo em que expressa sua livre e espontânea vontade em participar da pesquisa, ficando com uma cópia e entregando outra para o pesquisador. O pesquisador responsável por este estudo, sempre que solicitado, estará à disposição para esclarecer qualquer questão relacionada à pesquisa. Além disso, o paciente, a qualquer momento, terá total liberdade de recusar ou retirar seu consentimento e sair desta pesquisa, sem que isso lhe traga qualquer tipo de prejuízo.

Os resultados do estudo serão divulgados em congressos científicos e publicados em revistas especializadas, mas sempre preservando a identidade do paciente. Ressaltamos, também, que nem os pesquisadores e nem o paciente receberão qualquer remuneração financeira por participar desta pesquisa. 


\section{CONSENTIMENTo Pós-INFORMAdo}

$\mathrm{Eu}$, abaixo assinado, declaro que fui esclarecido sobre o objetivo do presente estudo, sobre eventuais desconfortos que poderei sofrer, assim como sobre os benefícios que podem resultar do estudo. Concordo, portanto, em participar, na qualidade de paciente, do referido Projeto de Pesquisa, sob livre e espontânea vontade.

de de

Assinatura 


\section{Anexo 2}

\section{Questionário}

Perfil de citocinas inflamatórias em indivíduos submetidos a procedimentos cirúrgicos empregando propofol ou isoflurano

Registro hospitalar do paciente

Código do indivíduo no estudo:

Data

\section{I - Identificação}

01-Nome

02-Sexo ( ) masculino ( ) feminino

03-Raça ( ) branco ( ) amarelo ( ) mulato ( ) negro ( ) outra:

04-Data nascimento 1

05-Idade

06-Peso

07-Altura

08-IMC (índice de massa corpórea)

09-Origem (cidade)

10-Profissão

\section{II - Informações gerais}

11-Considera sua alimentação saudável? ( ) sim （ ) não

12-Come frutas? ( ) sim ( ) não

13-Se sim, com que frequiência?

14-Come verduras? ( ) sim ( ) não

15- Se sim, com que frequiência?

16-Come carboidratos? ( ) sim ( ) não

17-Se sim, com que frequiência?

18-Come frituras? ( ) sim ( ) não

19-Se sim, com que freqüência?

20-Faz exercícios regularmente? ( ) sim ( ) não

21-Se sim, qual tipo (musculação, caminhada, etc)?

22-Se sim, quantas vezes por semana?

23-Fuma? ( ) sim ( ) não

24-Se sim, há quanto tempo?

25-Quantos cigarros/dia?

26-Qual tipo (cachimbo, charuto, palha, papel com filtro, etc)?:

27-Já fumou? ( ) sim ( ) não

28-Há quanto tempo deixou de fumar?

29-Quantos cigarros/dia fumava?

30-Durante quanto tempo fumou?

31-Tipo:

32-Consome bebida alcoólica? ( ) sim （ ) não

33-Se sim, quanto por semana (copos)?:

34-Tipo de bebida (cachaça, cerveja, uísque, vinho, etc)?

35-Já consumiu bebida alcoólica? ( ) sim ( ) não

36-Há quanto tempo deixou de beber?

37-Consome drogas? ( ) sim ( ) não

38-Se sim, qual?

39-Há quanto tempo? 
40-Tem contato com substâncias tóxicas? ( ) sim （ ) não

41-Se sim, qual (produtos de limpeza, agrotóxicos, gasolina, tinta)?

42-Há quanto tempo?

43-Foi submetido a raio $\mathrm{X}$ recentemente (dentário ou antes da cirurgia)? ( ) sim ( ) não

44-Quando?

45-Sabe quantas chapas de RX foram feitas?

46- Já fez tratamento com quimioterápico ou radioterapia? ( ) sim （ ) não

47-Se sim, qual?

48-Há quanto tempo?

49-Tem alguma doença (hipertensão, diabetes, hepatite, câncer, etc)? ( ) sim （ ) não

50-Qual?

51-Já teve alguma doença grave? ( ) sim ( ) não

52-Se sim, qual?

53-Há quanto tempo?

54-Passou por algum estresse ultimamente? ( ) sim ( ) não

55-Se sim, qual?

\section{III - História Médica}

56-É alérgico a algum tipo de medicamento? ( ) sim ( ) não

57-Se sim, qual?

58-Faz uso de algum tipo de medicamento (antibiótico, anti-inflamatório, analgésico, anti-hipertensivo, anti-convulsivante, insulina, hipoglicemiante)? ( ) $\operatorname{sim}$ ( ) não

59-Se sim, qual (is)?

60-Frequência/dia:

61-Faz uso de vitamina (complexo vitamínico)? ( ) sim ( ) não

62-Se sim, qual (is)?

63-Frequência/dia:

64-Há quanto tempo?

65-Tomou alguma medicação no último mês (remédio para pressão, antibiótico, tranquiilizantes, remédio para tirar a dor, antiácidos, anti-histamínicos, corticóide)?

( ) $\operatorname{sim}$ ( ) não

66-Se sim, qual (is)?

67-Frequência/dia:

68-Há quanto tempo parou?

69-Já fez alguma cirurgia? ( ) sim ( ) não

70-Se sim, quantas?

71-Há quanto tempo foi a última?

72-Já foi submetido à anestesia? ( ) sim （ ) não

73-Se sim, sabe o tipo de anestesia (local, geral, raquídea, regional)?

74-Há quanto tempo?

75-Se sim, você sabe se é mais resistente ou sensível a algum anestésico? 